\title{
Wayfinding in University Settings: A Case Study of the Wayfinding Design Process at Carleton University
}

\author{
by \\ Kehinde Oyelola \\ A thesis submitted to \\ the Faculty of Graduate and Postdoctoral Affairs \\ in partial fulfillment of the requirements for the degree of \\ Master of Design \\ in \\ Industrial Design
}

Carleton University

Ottawa, Ontario

(C) 2014, Kehinde Oyelola 


\begin{abstract}
This research focuses on the complex issues that pertain to wayfinding within a university campus. The research centers on Carleton University in Ottawa, Canada, as a specific case study. In addition to a literature search on issues of wayfinding in such environments, primary research engaged several stakeholders at Carleton University, which served as the bases for the methods of investigation. The three methods of collecting evidence were semi-structured interviews with organisation staff and design consultants, an online survey of end-users and finally an archival document analysis that related these findings to policies and general documentation available through Carleton websites.

The study examined best practice at Carleton University. During that examination, it was concluded that designers have a role to play in terms of providing effective, functional and useful wayfinding design, which should be included earlier in the design process. In addition, designers need to be aware of inclusive activities, such as understanding the importance of special populations (i.e. people with disabilities and other outliers). Furthermore, consideration of such needs may result in creativity and innovation that goes beyond the typical aesthetic standards.
\end{abstract}

Keywords: Wayfinding, accessibility, spatial design components, spatial communication, human performance, inclusive design, outliers, participatory design process, social participation 


\section{ACKNOWLEDGMENT}

Firstly, I am grateful to God for Life, without which I would not be here.

Thank you to Professor Bjarki Hallgrimsson, Professor Lois Frankel and Professor Federica Goffi for your support and advice, which has been instrumental to the completion of this thesis. In addition, thank you to Valerie Daley for ensuring that I finish in good time.

To the participants in the interview and respondents to the survey, thank you for your time and contribution; they were extremely relevant to the outcome of this study.

To my family, Mrs. Oyelola, Kemi, Kola, for your unwavering support, encouragement and input: you were available when I needed you most. Also, to my siblings, thank you for cheering me on. Lastly, thank you to my friends. I appreciate you all. 


\section{TABLE OF CONTENTS}

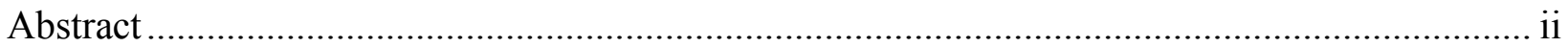

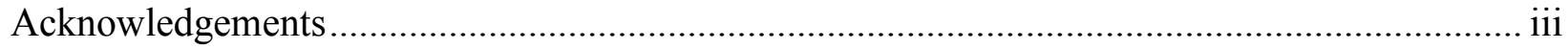

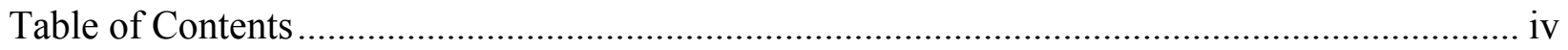

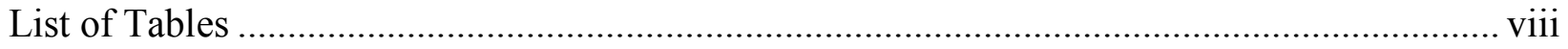

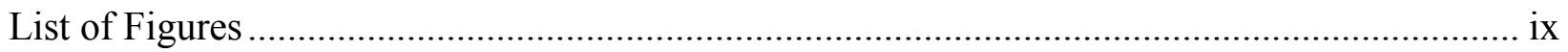

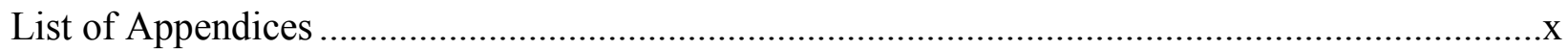

\section{CHAPTERS}

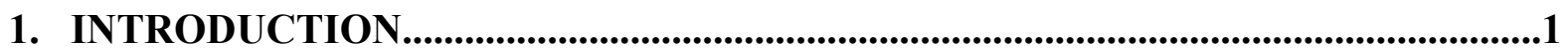

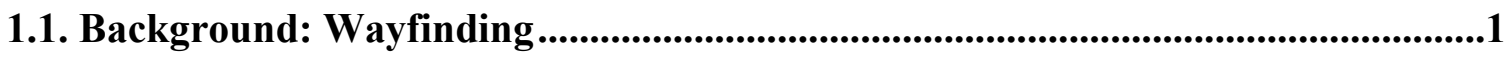

1.2. Wayfinding at University Campuses ..............................................................................2

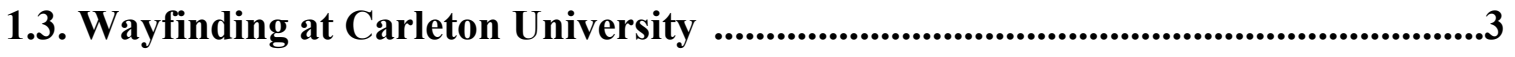

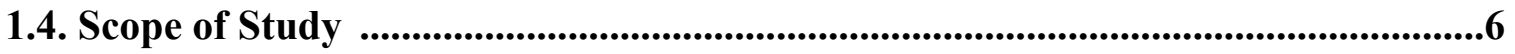

1.5. Contribution

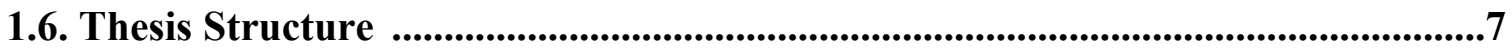

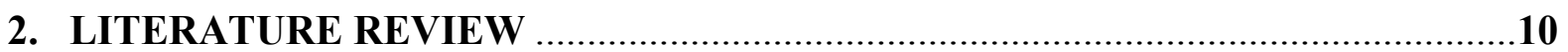

2.1. Introduction ........................................................................................................................10

2.2. Wayfinding and Accessibility in Complex Public Environments ........................11

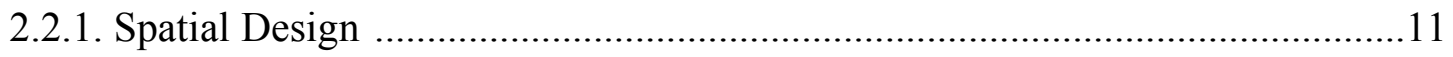

2.2.2. Spatial Communication: Graphic Information System ...............................12 
2.2.3. Extreme Conditions

2.3. Human Performance and Inclusion .......................................................................16

2.3.1. Human Performance and Wayfinding ……………...................................16

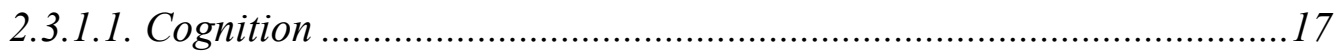

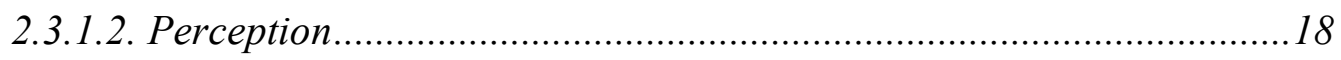

2.3.2. Wayfinding: Accessibility and Inclusion in Complex Environment ...............20

2.4. Inclusive Design in Practice ...........................................................................................21

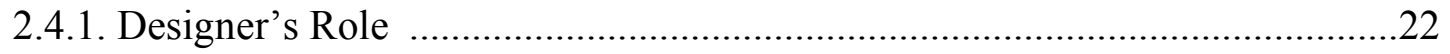

2.4.1.1. Design Effectiveness and Functional Usability ...............................22

2.4.2. Contemporary Approach to Wayfinding Design: Evidence in Practice .........26

2.4.2.1. Teresa Sapey: Car Park Puerta America Hotel ................................26

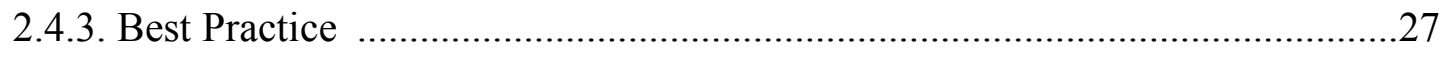

2.5. Evidence-Based Design Research in Practice ................................................................31

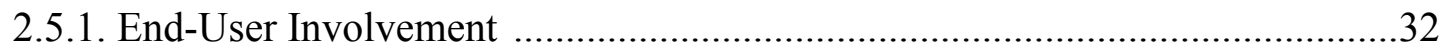

2.5.2. Facility/Infrastructure Evaluation ..................................................................33

2.6. Literature Summary ….........................................................................................................34

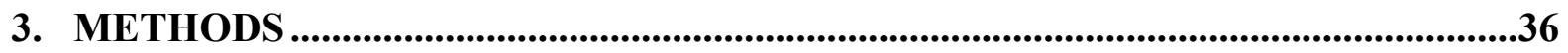

3.1. Introduction ......................................................................................................................36

3.2. Evidence Source 1: Semi -Structured Interview ..........................................................37

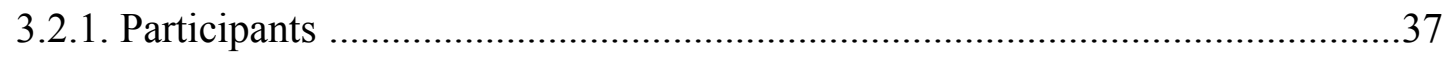

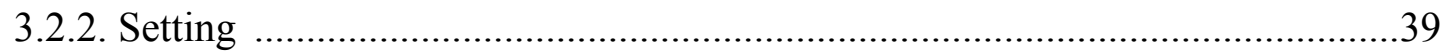


3.2.3. Data Collection Procedure ………………………........................................

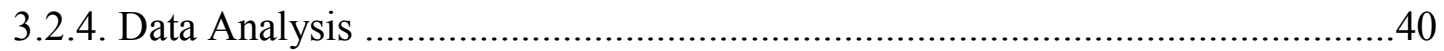

3.3. Evidence Source 2: Survey (Online) ................................................................................40

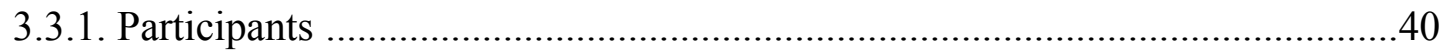

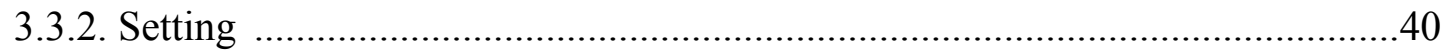



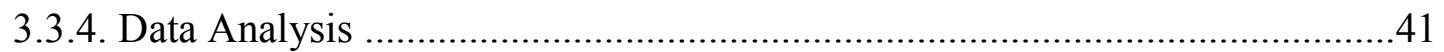

3.4. Ethics ….............................................................................................................................42

3.5. Evidence Source 3: Archival Document Analysis .......................................................42

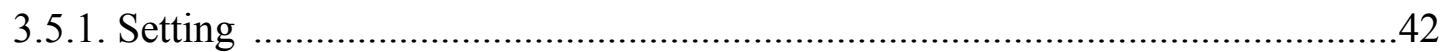

3.5.2. Data Collection and Analysis ………………………………........................4

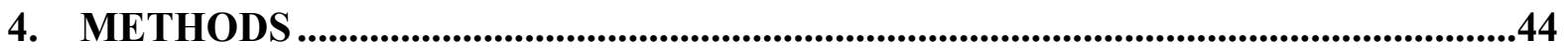

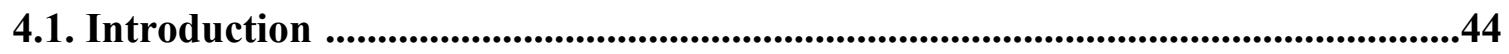

4.2. Evidence Source 1: Semi -Structured interview .........................................................44

4.2.1. Carleton University (Contextual Aspects) ………….......................................45

4.2.2. Carleton University (Strategic Aspects) ……………………………............47

4.2.3. Carleton University (Interdisciplinary Aspects) ...........................................50

4.2.4. Carleton University (Social Participation) …………………………….........51

4.3. Evidence Source 2: Survey (Online) ..............................................................................52

4.4. Evidence Source 3:Archival Document Analysis .........................................................59

4.5. Result Summary ...................................................................................................................60

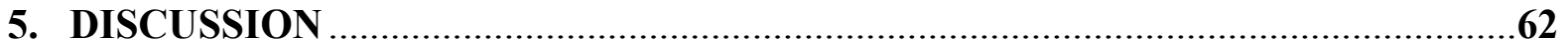


5.1. Best Practices at Carleton University

5.2. Improving Best Practice at Carleton University .................................................63

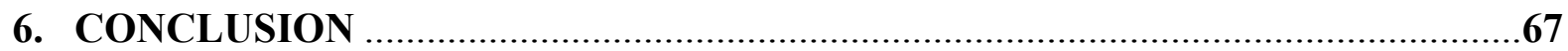

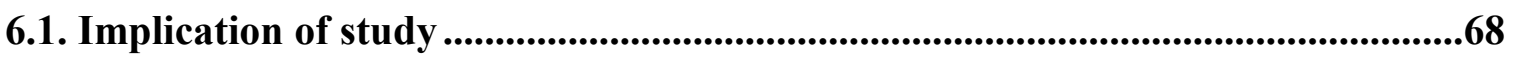

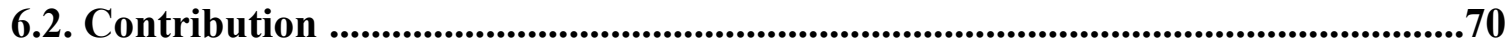

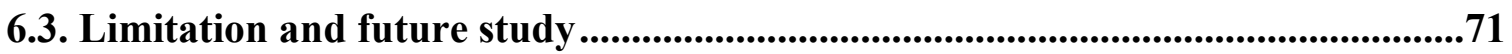

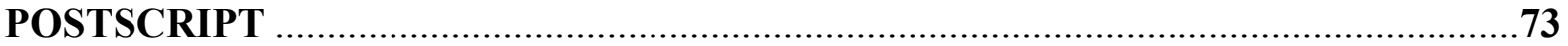

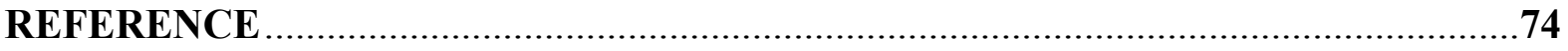

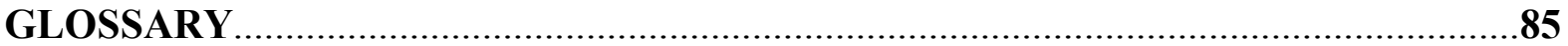

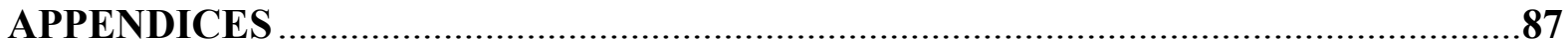




\section{LIST OF TABLES}

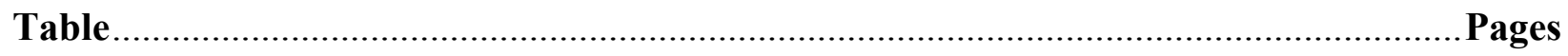

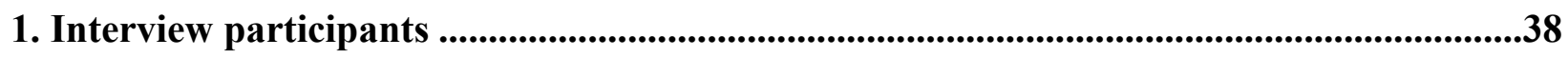




\section{LIST OF FIGURES}

Figure

Page

1. Carleton University: Spatial layout features ...................................................................4

2. Carleton University: graphic information system (Maps and signs) .......................................5

3. Evidence based methods (Primary research) structure .....................................................8

4. Evidence based methods (Primary research) Categories .................................................8

5. Evidence based methods (Secondary research) structure ..............................................10

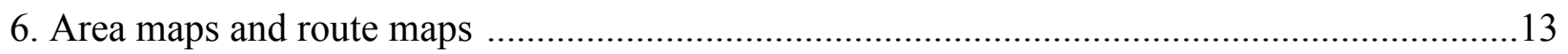

7. Car Park Puerta America Hotel by Teresa Sapey .............................................................27

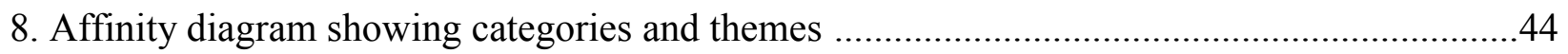

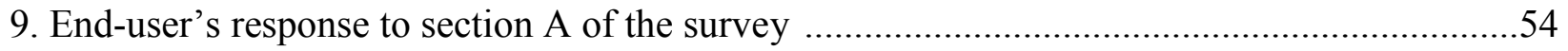

10a. Spatial design (activities) and icon keys: Ease of use (mean) .........................................55

10b. Spatial design (activities): Ease of use (standard deviation) ............................................56

11a. Spatial design characteristics: Level of significance (mean) ..........................................57

11b. Spatial design characteristics: Level of significance (standard deviation) .........................57 


\section{LIST OF APPENDICES}

APPENDIX A. Semi-Structured Interview (Introductory Emails) .......................................87

APPENDIX B. Semi-Structured Interview (Consent Form) ................................................91

APPENDIX C. Semi Structured Interview (Expert and Staff Interview Questions) ...................94

APPENDIX D. Survey - Online Questionnaire (Recruitment email) .....................................97

APPENDIX E. Survey - Online Questionnaire (Consent Form) ..........................................100

APPENDIX F. Survey - Online Questionnaire (Questions) ..............................................103

APPENDIX G. Survey - Online Questionnaire (End-User Comments and Suggestions) .........107

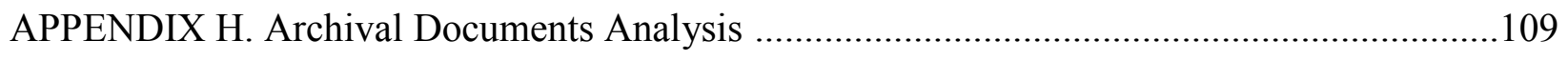

APPENDIX I. Carleton University Spatial Layout \& Proposed Development..........................112

APPENDIX J. Interview Quotes (Converging Categories and Themes) ...............................116 


\section{CHAPTER 1 INTRODUCTION}

\subsection{Background: Wayfinding}

The concept of wayfinding has existed since the sixteenth century. Initially, it was referred to by the term "wayfaring," which means travelling on foot to a certain destination (Arthur \& Passini, 1992). Over the years, however, design professionals, architects, urban planners, graphic designers and environmental psychologists have developed the term wayfinding to describe the navigation of one's environment. The term itself is continually evolving based on personal experience and empirical evidence based on the use and occupation of complex environments by end-users.

In 1960, Kelvin Lynch, an American architect and planner, published the first book on wayfinding. This book, The Image of the City, described wayfinding from an urban perspective, using concepts such as spatial orientation and cognitive mapping (or environmental imaging). These concepts refer to an end-user's ability to represent the physical environment mentally. Typically, past and present experiences of a city provide information for navigation. Lynch further explained that these experiences are based on environmental components such as paths, edges, landmarks, nodes and districts. These concepts and components form the foundation for wayfinding design theory as it is presently used.

In the early 1970s, a pair of environmental psychologists, Rogers Downs and David Stea, contributed to Lynch's argument and stated that fundamental processes such as environmental perception, cognition and decision-making should be considered as part of successful spatial orientation. They argued that understanding end-users' relationships and movements in complex environments in terms of these processes adds another dimension to the definition of wayfinding. 
Subsequently, in the 1980s, the architect and environmental psychologist Romedi Passini described wayfinding from the perspective of the built environment. In addition to the information stressed by Lynch, Downs and Stea, Passini encouraged the use of empirical evidence such as interviews and surveys to get end-users' feedback. Consultation with endusers helps to identify issues end-users face when navigating complex environments, which can include illegible wayfinding maps and signs, confusion about evacuation in emergency situations and barriers to accessibility. These accessibility barriers could be physical, psychological or sensorial, all of which can reduce ease of movement in complex environments. Passini further argued that designers have a role to play in ensuring effective wayfinding design that is functional and useable by every individual. This process, which involves a team of architects, planners, graphic designers and environmental psychologists, goes well beyond simply consulting a graphic designer after the spatial layout of the built environment has been completed.

\subsection{Wayfinding at University Campuses}

Wayfinding in complex public environments, for example university campuses, has been known to cause issues of functional inefficiency, barriers to accessibility and safety concerns during emergencies (Passini, 1984). These issues, which can result in stress, frustration, time loss and even death, impact end-users in different ways (Arthur \& Passini, 1992; Evans \& McCoy, 1998). Stress and frustration has been linked to disorientation in complex environments, especially for visitors in unfamiliar environments (Haake et al., 1984; Arthur \& Passini, 1992; Chang, 2013). These experiences can lead to public relation issues that negatively affect an organisation's reputation (Passini, 1984). Some organisations use graphic information systems such as signs to prevent disorientation (Vanderklipp, 2006). However, 
signage can cause more harm than good in instances where signs are illegible, unreadable or unclear (Stevenson, 1990; O'Neill, 1991; Arthur \& Passini, 1992). Signs are useful only when they complement effective circulation systems. If the setting is well designed, signs will act as a support in navigation (Arthur \& Passini, 1992).

Consequences of inadequate wayfinding systems include lost professional time and productivity, as staff direct visitors to their destination (Arthur \& Passini, 1992). Even more seriously, if paramedics and firefighters are not able to locate emergency scenes in good time, injury and even death can occur (Arthur \& Passini, 1992).

Accessibility is another crucial issue in wayfinding. Accessibility is impeded when endusers with various disabilities (such as physical, psychological and sensory) have difficulty accessing complex public environments. This issue causes physical and psychological barriers to mobility and full participation within these environments (Passini, 1984; Arthur and Passini, 1992).

\subsection{Wayfinding at Carleton University}

This study was conducted at Carleton University, which is located in the Canadian capital city of Ottawa. This site was chosen because of its proximity and its large size, as well as its strategic aim to be an accessible and inclusive institution. The following section serves as an overview of the campus setting, overall size and layout and other contextual information.

\section{Spatial Layout:}

The campus was built on a slope and is bounded by the Rideau Canal and Rideau River. Occupying roughly 0.62 square kilometers, the campus is divided into four distinct zones: western and eastern academic, residential, middle and northern administrative buildings (see 
appendix I). Within these zones are forty-three buildings including departmental buildings, lecture halls, dormitories, fitness facilities, a library, and so on. Circulatory systems link the campus to the city as well as the buildings to each other. These circulatory systems include bicycle paths, pedestrian walkways and roads for cars and buses, as well as restricted roadways for service vehicles. In addition, the local O-Train commuter system services the campus with links to the city and a shopping centre. A system of tunnels spans all the buildings on campus and was built to allow indoor access between buildings all season long, especially during winter; the tunnels also serve as a route for service vehicles (see Figure 1).

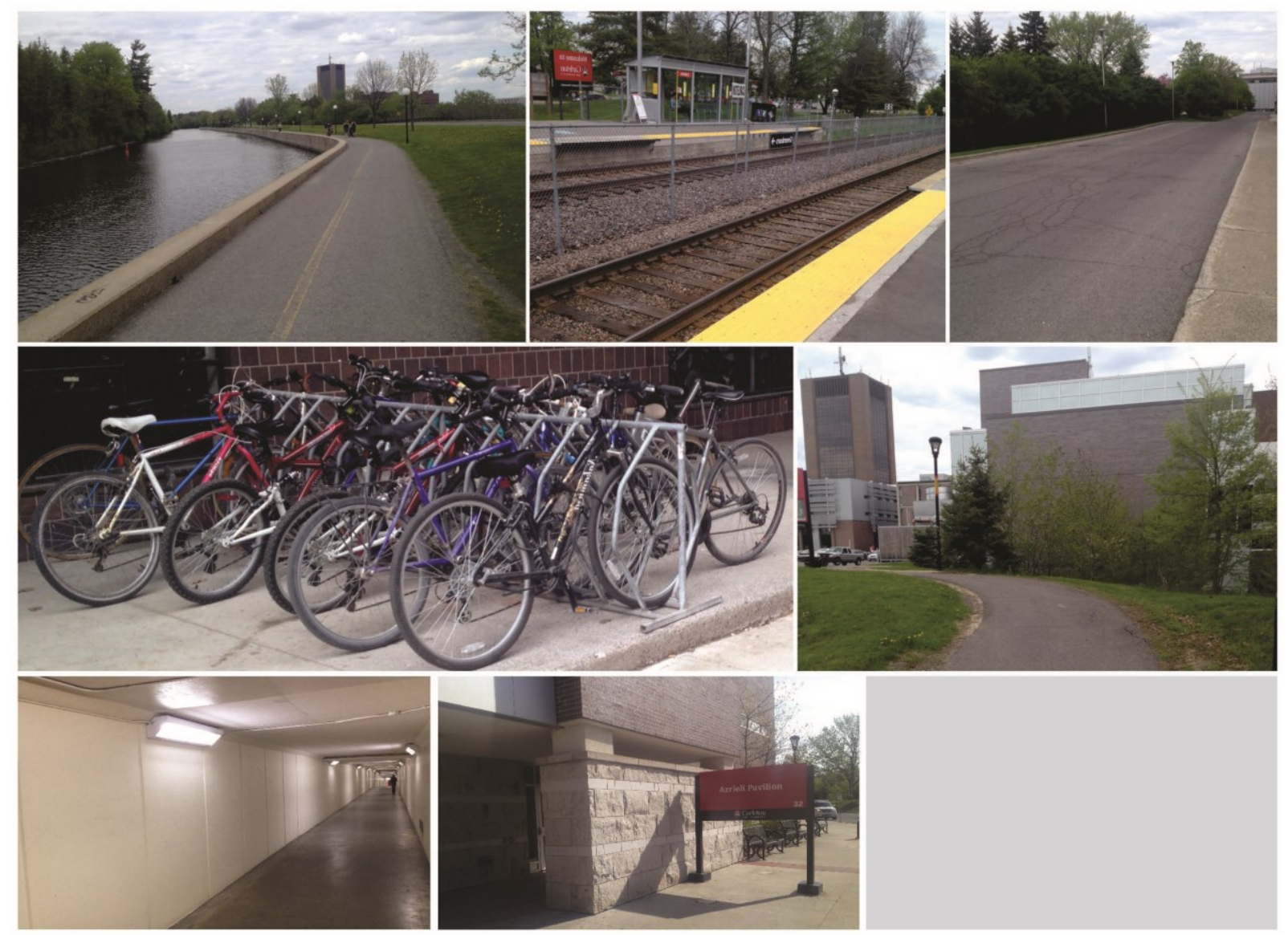

Figure 1. Carleton University: Spatial layout features (Oyelola, 2014) 


\section{Spatial Communication: Graphic Information Systems:}

Carleton University has two types of graphic information systems, maps and signs.

Carleton's signs are classified into four types (see Figure 2), and comprise both exterior and interior signs. The exterior signs provide wayfinding information for vehicular traffic and pedestrians outside buildings, while the interior signs provide wayfinding information for endusers within buildings, especially in the tunnels. In addition, there are numerous emergency exit signs.

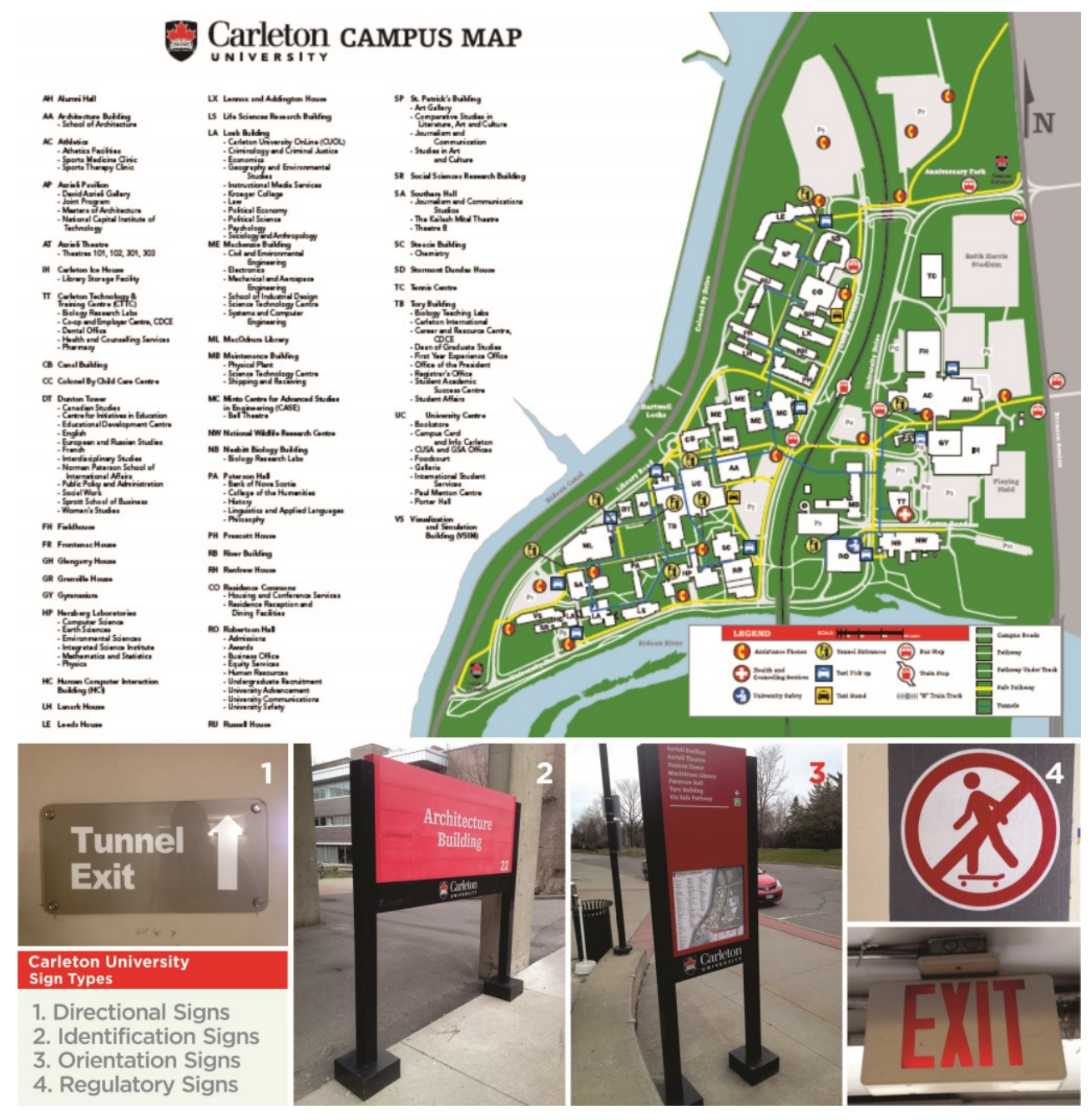

Figure 2. Carleton University: graphic information system (Maps and signs) (Oyelola, 2014) 


\section{Purpose of Study:}

Social participation in spatial design development is crucial to the social, environmental

and psychological well-being of end users (Imrie, and Hall, 2001). When professional designers with substantial experience in the design and planning of wayfinding were asked about their own involvement in the planning stages, they indicated that they were seldom included at the initial stage of design projects. Research demonstrates that this can lead to end-users experiencing stress, frustration and functional inability; it also can lead to barriers to people with disabilities and can compromise safety in emergency conditions (Arthur \& Passini, 1992; Bühler, 2001; Sebring-Cale, 2008; Imrie, 2012; Steinfeld, \& Maisel, 2012).

The study aimed to investigate the role of designers and end-user involvement in the wayfinding design process. In particular, the study was conducted to investigate how and when various stakeholders can be included to improve wayfinding systems at Carleton University.

\subsection{Scope of Study}

The research investigates wayfinding on a university campus, where many different requirements, including transportation and movement, have to be examined in the specific context of accessibility and safety for people with varying levels of ability. The research examined the wayfinding system at Carleton University from an interdisciplinary context. This included consulting different stakeholders, comprising designers, administrators and various end-users. The literature review drew evidence from various disciplines including spatial planning, environmental graphic design, and psychology and design research. This was intended to provide understanding into how interdisciplinary aspects affect current wayfinding design and planning practices on campus and to see if insights would emerge that could aid the process of such design efforts in the future. 


\subsection{Contribution}

This study is intended to benefit professionals, academics and university campus stakeholders such as architects, urban planners, industrial designers, environmental psychologists, facility managers, campus organisation staff and students. The insights from this study may be useful for developing new and existing wayfinding design projects in similar contexts.

From a social participatory point of view, the study proposes recommendations towards identifying stakeholders and understanding their interdisciplinary roles, as this will encourage collaboration for effective decision-making. In addition, the study recommends further improvements to best practices. This safeguards effective outcomes with regards to wayfinding at Carleton University. Recommendations include early involvement of designers in wayfinding design projects and understanding end-users and outliers in order to improve functional usability as well as usefulness. This requires that designers also consider end-user involvement. Evidence-based research methods can be used to evaluate and understand endusers' experiences and perceptions of accessibility and wayfinding.

\subsection{Thesis Structure}

Chapter One presents the case study context highlighting the need, purpose and scope of the study. This chapter also elaborates on the boundaries of this study as well as the contributions to the field this study makes.

Chapter Two explores the secondary research through a literature review that serves as the basis for the primary research and analysis in the case study. The interdisciplinary research areas were categorized as contextual research, psychological research, design practice and basis for design research. This research included literature on accessibility and wayfinding in 
complex environments and literature on human performance and diversity, as well as inclusive design in practice. The secondary research also covered literature on evidence-based research methods, which served as the basis for the primary research at the case study site (Carleton University).

Chapter Three elaborates on the evidence-based research methods used for the primary research. The methods used were mostly qualitative, including open-ended semi-structured interviews, surveys and archival document analysis (see figure 3 below). The results were triangulated to reveal converging themes and categories that aligned with the secondary research evidence. The settings, participants, data collection procedures and data analysis are also discussed in this chapter. Participants involved in the research were divided into three groups: Stakeholder 1 (design consultants), Stakeholder 2 (organisation staff) and Stakeholder 3 (end-users).

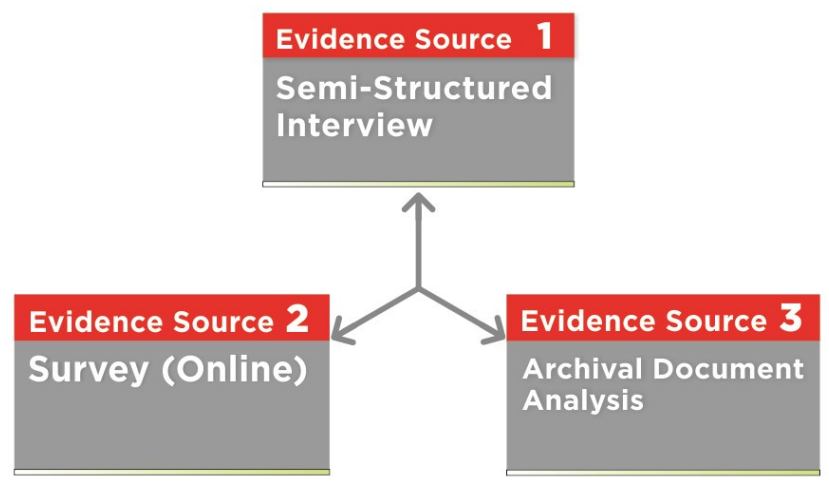

Figure 3. Evidence based methods (Primary research) structure (Oyelola, 2014)

\section{Carleton University
Contextual Aspect}

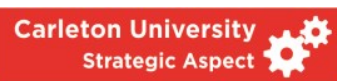

Strategic Aspect
Carleton University

Interdisciplinary Aspects
Carleton University Social Participation

Figure 4. Evidence based methods (Primary research) Categories (Oyelola, 2014) 
Chapter Four presents the results of the data collection and analysis from the primary research. Findings were organised according to emerging categories and themes. The findings gave insights into the major concepts in four areas within the Carleton University context, namely contextual, strategic, interdisciplinary, and social participation (see figure 4). The contextual aspect provided insight into the structural composition of the case study site and the strategic aspect provided insight into the psychological aspect of wayfinding as well as strategies employed in design practice to achieve inclusion. In addition, the interdisciplinary aspect involves stakeholder identification, participation and level of involvement. The social participation aspect also dealt with end-user involvement; end-users provided their perspectives and perceptions through evaluations.

Chapter Five presents discussions based on findings from the results of the data collected. These discussions attempted to provide answers to the research questions. In addition, the researcher synthesized the concepts from the secondary research with the discussions and evidence that emerged from primary research. This synthesised approach provided responses to the research questions.

Chapter Six concludes the research and presents the chief points emerged from the research. This chapter also highlights the implications of this study and its contribution to knowledge for both stakeholders and the design field. 


\section{CHAPTER 2 \\ LITERATURE REVIEW}

\subsection{Introduction}

This chapter explores the various literature obtained from diverse fields, such as architecture, planning, environmental psychology, environmental graphic design and design research. These knowledge areas serve as the basis for the primary research. The literature has been examined from 4 viewpoints: wayfinding and accessibility in complex environments, human performance and inclusion, inclusive design in practice as well as evidence based design research (see Figure 5 below).

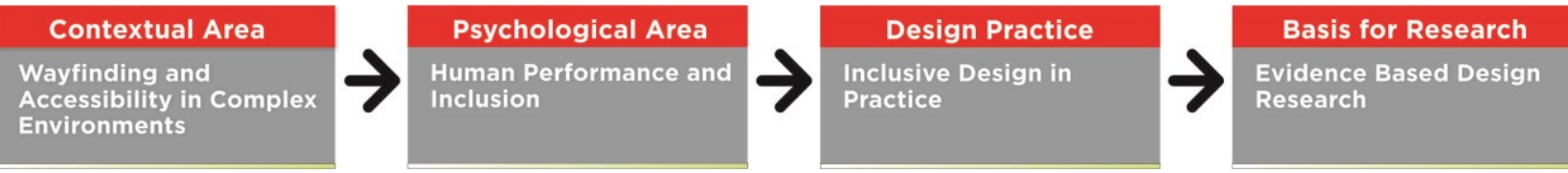

Figure 5. Literature review (Secondary research) structure (Oyelola, 2014)

The first section supplies the context of this secondary research and discusses the spatial design and communication features that aid the wayfinding process in complex environments. It also discusses the impact of wayfinding for people with disabilities and in extreme conditions such as emergencies.

The section on human performance and inclusion discusses the psychological activities involved in wayfinding, which include using cognitive process to mentally represent the physical environment and perceptive processes to obtain spatial information by decisionmaking. The inclusion aspect discusses individual differences that exist with diverse end users when navigating complex environments. 
The section on inclusive design in practice discusses the role of stakeholders in ensuring an inclusive environment. These roles involve design for effectiveness and functional usability. In addition, this section discusses professional practice and processes involved in wayfinding design for new and existing projects.

The last section discusses the participatory process between stakeholders and end users. This process takes into account design research methods required to engage end users in meaningful dialogue to generate feedback that could be used in wayfinding design development.

\subsection{Accessibility in Complex Public Environments}

The particular characteristics of an environment's layout determine the kind of wayfinding design necessary to ensure accessibility. Understanding this from the initial design stage is essential to identifying issues end-users might encounter (Heft, 1979; Passini, 1984; Peponis et al., 1990; McCormick, 1996). Investigation of these issues might reasonably benefit from studying the perceptive processes involved in making decisions and plans based on spatial information (Arthur \& Passini, 1984). However, wayfinding and accessibility issues are also linked to spatial design components, which is to say spatial layout and circulation systems (Passini, 1984).

\subsubsection{Spatial Design Components}

Spatial layout and circulation systems are design components that must be considered when determining issues that end-users might encounter in complex environments. This is because end-users need to understand both the spatial layout structure of a complex environment and its circulation systems (Passini, 1984). These components, according to Lynch 
(1960), can be categorized as five design features: paths, edges, districts, nodes and landmarks. For the purpose of this study, paths refer to the internal and external pathways of a complex environment, such as floors, walkways, roads and railroad tracks. Edges are physical boundaries such as walls; districts are enclosed spaces such as rooms and offices; nodes are focal points or central meeting points, and landmarks are clearly visible features of the environment such as buildings.

Lynch (1960) and Weisman (1981) both argue that these design features of spatial design component help promote environmental legibility, especially in complex environments. Passini (1984) also added that these five design features work together as cues to guide endusers to their destinations.

\subsubsection{Spatial Communication: Graphic Information System}

Since the goal of spatial design components is to provide environmental legibility, effective spatial communication is essential. This demands that a number of interrelated systems function well, given that design features are architectural cues that serve as guides, with graphic information systems such as maps (Levine, 1982) and signs (Stevenson, 1990; O'Neill, 1991) complementing them (Passini, 1984). A number of issues within and between these systems can inhibit wayfinding, ranging from dysfunctional signage (Stevenson, 1990; O'Neill, 1991) and maps (Levine, 1982) to deficiencies in design features such as pathways

(Peponis et al. 1990; Zacharias, 2001), floor layouts (Garling et al., 1990; O'Neill, 1991) and site topography (Passini, 1984; Garling et al., 1990; O'Neill, 1991; Huang, 2013). 


\section{$\underline{\text { Maps }}$}

With origins dating back to around 2500 BCE (Beck and Wood, 1976), physical maps are one of the oldest graphic information systems available to end-users to help them navigate unfamiliar or complex environments. Maps indicate orientation, routes to destinations and locations of final destinations. Maps enable users to orient themselves in relation to their environment.

Cartographers divide their maps into categories such as land maps and plans, and maps vary greatly depending on the scale and level of details (Mollerup, 2005). Maps present information relevant to different wayfinding tasks. Area maps outline specific areas such as a specific faculty building on a university campus map (see Figure 6). Route maps are more schematic in nature, outlining only the route path to a specific destination, as seen in train and bus route maps (Mollerup, 2005). In area maps, the five design features of the spatial design components mentioned in section 2.2.1. are crucial. These features—-paths, edges, districts, nodes and landmarks (Lynch, 1960) — are usually represented graphically, either horizontally or vertically depending on the context of use (Levine, 1982; Gibson, 2009).
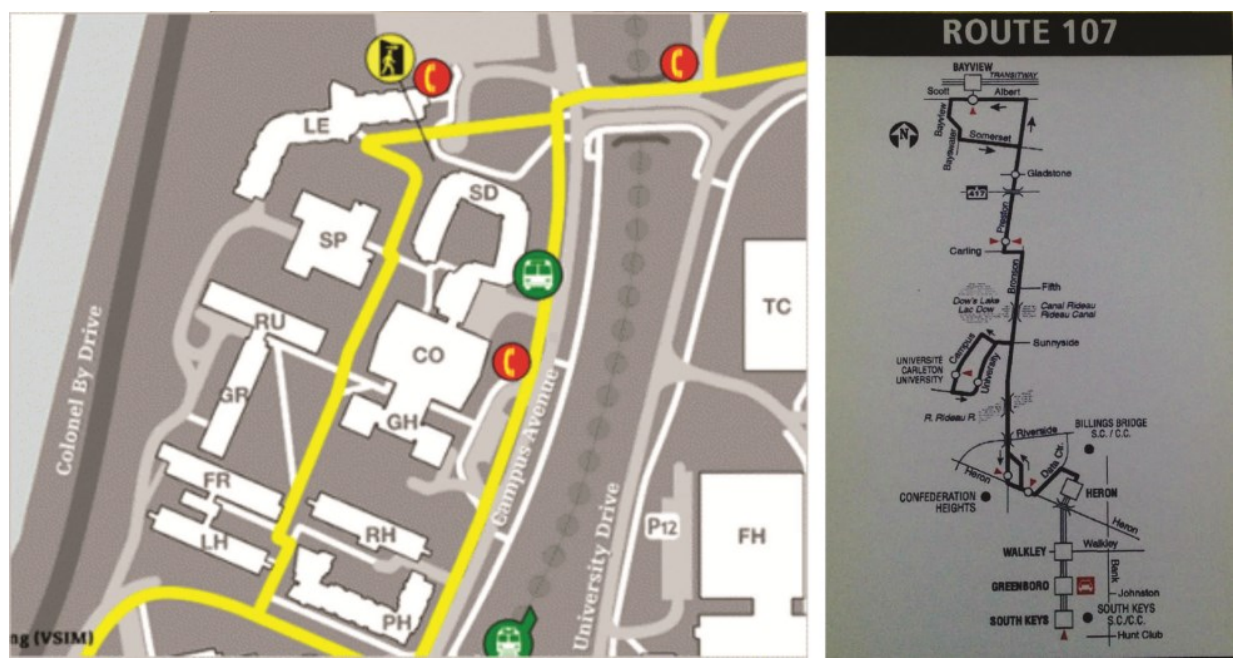

Figure 6. Area maps and route maps (Oyelola, 2014) 
The amount of visual information on any map is an important aspect related to the maps function. The information load must be determined accordingly; if there is more information than required on the map, the information overload can inhibit effective cognition and perception of spatial information (Passini, 1984). A map's orientation might also inhibit effective comprehension of spatial information. Based on research they conducted on maps and orientation, Levine et al. (1984) suggest that maps are most effective when the orientation on the ground matches that on the map. This means that map orientation should align with the enduser's position in the physical environment. Overall, the simpler the map, the easier it is for end-users to find their way (Borun, 1977; Talbot et al., 1993; Bell et al., 1996).

\section{$\underline{\text { Signs }}$}

Signs are another graphic information system end-users utilize when finding their way (Passini, 1984; Arthur \& Passini, 1992; Gibson, 2009). Signs complement circulation systems and function as cues to a particular destination (Ford \& Torok, 2008). They are classified into four categories: directional signs, identification signs, orientation signs and regulatory signs (Gibson, 2009).

As the name implies, directional signs direct end-users to their destination. They are characterised by the use of texts, arrows or symbols. Identification signs describe a place and help end-users identify a destination. These can be portable or fixed to a wall, floor or any flat surface for ease of visibility, and are typically characterised by bold text. Identification signs are extremely useful in public places, identifying end-users' destinations and sometimes communicating the value of a place (Passini, 1984; Gibson, 2009). Orientation signs include a combination of directional and identification signs, and might also include a schematic overview of a location. Their function is similar to an orientation map, but with signs and texts 
that complement the map. Regulatory signs are usually restrictive in that they highlight what is permitted and prohibited. They are not as large as the directional and identification signs; however, they clearly communicate regulatory messages governing a particular location (Passini, 1984; Gibson, 2009).

We can easily understand the applications of the various types of signs in a university campus setting by imagining a student's daily activities. For instance, a student might decide to visit a school with the intention of locating a particular office. The student follows the directional signs and arrives at the desired destination, which has an identification sign indicating the room number and the room occupant's name. Having located the desired office, the student decides to go to class in another building. The student locates an orientation sign indicating the campus map and a directional sign pointing towards the location of the classroom. On the way to class, the student smokes a cigarette but exercises caution on seeing a no-smoking regulatory sign close to the classroom. This illustration depicts the typical use of signs in everyday life.

The information communicated by signs is important, and signs can be useful in situations such as selecting which route to take when in an unfamiliar environment (Chang, 2013) or during emergencies (Mollerup, 2005). A sign's efficiency can be measured in part by its size in relation to the environment and the approximate distance to the end-user (Arthur \& Passini, 1992). As is the case for maps, information overload is a risk for signs, and can inhibit the ability of end-users to process information.

\subsubsection{Emergency Conditions}

Apart from navigation of complex environments, wayfinding design is also crucial in planning for emergency conditions. Stress levels in emergency situations can affect 
wayfinding performance, as anxiety affects perceptive and cognitive abilities (O’Neill, 1992, Xie et al, 2012). Uncertainty and the perception of danger can also have an impact on wayfinding. As a result, designers consider consistency when designing wayfinding communication, as this achieves the dual function of reducing information overload and allowing for easy recognition and understanding (Arthur \& Passini, 1992).

If end-users understand an environment well, it will be easy to navigate during fire situations (Xie et al., 2012). One way of achieving this is by organising fire drills that train building occupants to understand the location of exits and alternative routes in case of a fire emergency (Arthur \& Passini, 1992).

\subsection{Human Performance and Inclusion}

This section explores some of the more salient psychological processes involved in the spatial understanding of complex environments. This mental aspect consists of the interaction between the individual's psychological processes and the character or features of complex environments.

\subsubsection{Human Performance and Wayfinding}

The ability to complete activities and tasks in a complex environment is crucial to the well-being of the end-user (Arthur \& Passini, 1992). Cognition and perception are two distinct aspects that play a major role in achieving well-being in complex environments (Passini, 1984).

Cognitive mapping or imageability (Arthur \& Passini, 1992) refers to the spatial understanding of end-users within an environment and involves the mental representation of spatial design components coupled with the ability to orient oneself within the space (Passini, 1984; Arthur \& Passini, 1992). It is important to note that wayfinding goes beyond cognitive 
mapping to include the perceptive process of spatial information processing, spatial decisionmaking and plan development, and execution of plans (Passini, 1984).

\subsubsection{Cognition}

This is a spatial problem-solving process that in the context of wayfinding involves an end-user's ability to mentally represent spatial features of complex environments, coupled with the ability to locate oneself within that representation (Evans et al., 1980; Schneider \& Taylor, 1999; Downs, 2001).

\section{Cognitive Mapping}

This spatial representation process involves using multiple viewpoints within an environment (Garling, 1989; Kitchin, 1994). A research study carried out by Passini (1984) in the 1970s and 1980s resulted in the conclusion that end-user movements follow two distinct map structures: (1) the sequential or egocentric map structure and (2) the coordinate or survey map structure. The former involves a systematic, turn-by-turn movement similar to the experience in underground train stations and tunnels, while the latter follows an identified holistic organisation principle.

For instance, when an end-user is in a complex setting, there is a tendency to use the sequential map structure initially, and then graduate to a coordinated structure. This is because it is not easy to visualize the entire environment at a glance, especially if the end-user is unfamiliar with the environment (Haake et al; 1984). It takes some time and repeated visits to capture the entire environment mentally (Guy et al., 1990). While these two cognitive structures have universal elements, research has also focused on variations in performance when dealing with spatial representation (Passini, 1984). These variations in performance are 
due to individual differences involving gender (Devlin \& Bernstein, 1995; Malinowski et al., 2001), culture (FARR, et al., 2012) and various disabilities such as physical and sensory disabilities (Sebring-Cale, 2008; Chan et al., 2009; Whitmer, 2009).

\subsubsection{Perception}

\section{Perceptive Process}

Perception involves the use of sensory and mental processes to obtain environmental information (Goldstein, 2010). These processes work together to ensure end-users obtain relevant information from the environment (Golledge, 1992). For the purposes of this study, these processes include obtaining spatial information, planning and decision-making and decision execution (Arthur \& Passini, 1992). Perception also provides support for tasks such as wayfinding in complex environments, especially for people with various physical and sensory disabilities (Arthur \& Passini, 1992).

Spatial information process: Given the large amount of information complex spatial environments contain, it is necessary to select which is relevant at the right time (Passini, 1984). Passini (1984) states that end-users usually perceive information directly related to the task they plan to execute during wayfinding. An example by Arthur \& Passini (1992) illustrates this well. Researchers described their observations of a Montreal hospital where the site had a slope and the hospital was designed and built to follow this site feature. There were two entrances, one at the second floor and the other at the fourth floor. The results showed that most of the users who were going to the upper floors used the fourth floor entrance because of the perception of a visual cue (staircase). The interpretation of this study was that the end-user perceived the information (staircase) directly related to the task (going to the upper floor). 
Route learning: Hirtle \& Hudson (1991) argued that acquiring information about new and unfamiliar environments requires processes such as spatial knowledge, where this process works with existing landmarks and spatial configurations (Xia et al., 2008).

Decision planning and execution process: The wayfinding decisions that end-users will make should guide both the message and the position in the spatial environment (Passini, 1984; Arthur \& Passini, 1992). Though this is just a single decision, practically speaking, it is better for designers to take the overall decision plan as a structural component, which contains a collection of individual decisions, strategic to solving wayfinding issues. In solving these issues there are two structural components that aid the completion of a wayfinding task: decision hierarchy and decision plan.

Decision hierarchy: This involves the hierarchical executions of tasks when the end-user has the overall task of locating a destination within a particular environment. An example is the case of an end-user who is given the task of delivering a package to another end-user in the same building (Passini, 1984; Arthur \& Passini, 1992). The major task is to locate the individual and deliver the package. Within this, however, there are sub-tasks each involving a single decision, and each of these is a contributing factor in the successful execution of the major task.

Decision plans: This involves the transformation of decisions within the decision hierarchy to actionable plans, where these plans lead to behavioral actions that might either successfully complete the task, or lead to another decision task (Passini, 1984; Arthur \& Passini, 1992). This dual possibility indicates the dynamic nature of the decision planning and execution process. Decision plans are crucial to wayfinding effectiveness during pre-occupancy development and post-occupancy evaluation of spatial design projects. This is because decision plans enable end-users to keep track of behaviours that direct them from their original location 
to their destination, and this can be used as empirical data in the design process (Arthur \& Passini, 1992). Decision plans at the pre-occupancy stage of a spatial design project are predetermined by identifying wayfinding issues using evidence-based research methods. Meanwhile, decision-making at the post-occupancy stage is usually determined by circulation systems such as walkways, stairs and elevators. However, wayfinding design problems sometimes result in insufficiently legible circulation systems, resulting in confusion and frustration (Passini, 1984). Passini (1984) described wayfinding problems as a function of the end-user's interpretation of a wayfinding task in relation to the spatial information available.

\subsubsection{Wayfinding: Accessibility and Inclusion in Complex Environment}

Discussions of the cognitive and perceptive processes involved in interpreting spatial information highlight similarities among end-users. However, the complexity of spatial information also means that individual variations affect interpretation, especially as the complexity of the interpretation increases (Passini, 1984; Kato \& Takeuchi, 2003). End-users with sensory impairments, especially visual impairment, usually find it difficult to navigate complex buildings (Passini, 1984; Danford 1999). Research has shown that those who have been blind since birth can form cognitive maps to guide their navigation. This cognitive process normally takes longer, however, than for those without visual impairment (Passini, 1984). This is because end-users who have been blind from birth have not had the experience of perceiving a physical environment; therefore, they have limited access to spatial information (Martins et al., 2010).

In tackling this limitation, designers can put tactile and auditory measures in place to aid the cognitive and perceptive processes. Tactile measures involve providing surfaces that people 
with visual impairment can feel (either by touch or physical contact). These surfaces function in four different ways (Dischinger \& Jackson, 2012):

(1) They warn of impending hazard or danger,

(2) They guide along the direction of travel,

(3) They serve as indicators at intersections, especially at junctions, and

(4) They serve as markers to a desired destination, e.g., a tactile flooring system that directs a visually impaired user to a reception desk in public environments (Dischinger \& Jackson, 2012). Tactile surfaces using Braille can also be used in numbering systems in elevators, as the use of Braille helps visually impaired users understand the information a sign is transmitting (Passini, 1984; Dischinger \& Jackson, 2012). Similarly, auditory measures use sound to communicate wayfinding information to visually impaired users (Sebring-Cale, 2008; Da Silva, 2010). Auditory measures can also help to ease the frustration that users with disabilities often face (Al-Tal, 2002; Gibson et al., 2013).

The following section addresses inclusion in practice, to determine how well tactile and auditory measures have been used, and their impact on diverse user groups (Imrie, 2012).

\subsection{Inclusive Design in Practice}

Design features such as building landmarks and architectural cues, with the support of graphic information systems, contribute to the degree of spatial accessibility of a complex physical environment (Passini, 1984). However, individual navigation strategies and challenges for people with various disabilities greatly affect accessibility, and the degree to which these strategies and challenges are anticipated determines how inclusive the built environment is (Arthur \& Passini, 1992). Thoughtful design is therefore crucial to developing inclusive environments that are accessible to every end-user. Having examined aspects of spatial design 
components, spatial communication features for wayfinding and accessibility, as well as psychological factors in human performance, it is expedient to explore the ways that inclusive design concepts can address these aspects.

This section investigates the origin, principles and practice of inclusive design in complex physical environments. This provides a foundation for considering the role of designers and best practices in developing functional and effective wayfinding designs in complex environments. This section also surveys the practices used by contemporary designers.

\subsubsection{Designer's Role}

Inclusivity is not a new concept; it has been around for over two millennia (Clarkson, 2003) and has its roots in design (Imrie \& Hall, 2001). The success of inclusive design has led to the adoption of inclusive principles in a variety of disciplines and practices around the world, such as economics, social science, health and the public sector (Clarkson, 2003). Many scholars have researched inclusive design in terms of health and the aging population (Clarkson, 2003), transportation and public transit (Imrie \& Hall, 2001), product design and assistive technology (Imrie \& Hall, 2001; Clarkson, 2003), as well as the built environment (Imrie \& Hall, 2001). This study, however, focuses on inclusive design in relation to the built environment, with specific reference to spatial and wayfinding design in complex environments.

\subsubsection{Design Effectiveness and Functional Usability}

Inclusive design in fact dates back to the first century, when the Roman architect and engineer Vitruvius argued that effective architecture should be based on three characteristics: firmness, delight and commodity. In modern terminology, these characteristics translate to structural stability, character or meaning and functional usability (Steinfeld \& Maisel, 2012). 
Character refers to the significance attached to a place and is related to aesthetics, which is itself a subset of character (Steinfeld \& Maisel, 2012). Functional usability, on the other hand, is the foundation of inclusive design and principles of functional usability have been instrumental in the design of domestic structures (Williams \& Williams, 1974). Domestic structures have been intended for everyday use and therefore have been customised to accommodate economic, environmental and social factors (Alexander 1964; Rapoport 1969).

Design became increasingly professionalized in the 1800 's, during the Industrial Revolution. Both the private and public sectors hired design professionals, who often commanded high prices for their services. During this period, the focus of the built environment shifted from functional usability to character (Steinfeld \& Maisel, 2012). The post-industrial or modern era witnessed a re-thinking of the design profession spearheaded by the early twentiethcentury Chicago architect Lois Sullivan in which functional usability again became a priority (Steinfeld \& Maisel, 2012).This resulted in the widescale adoption of innovations such as elevators, electricity and information exchange media in the domestic sphere.

Architects and designers also aimed to improve the standard of living and provide affordable housing. Especially in the post-WWII period, these aims were actualized in urban development plans and prototype housing schemes such as row houses and medium-rise housing (Rainwater, 1966). While these developments were seen as effective according to some measures, Boudon (1972) argued that in fact these developments were neither effective nor functional, leading to alienation, unhealthy living conditions and increased crime (Frumkin, 2006; Marshall et al., 2009; Schweitzer \& Zhou, 2010).

During the late 1960s, prompted by a sense of social responsibility, designers preferred user-centered and interdisciplinary approaches to achieving usefulness in the built environment. Accordingly, interdisciplinary professionals such as architects, planners and social scientists 
coordinated their efforts in order to create standards and policies that focussed on end-users (De Couvreur, \& Goossens, 2011). This approach has persisted to the present day, and designers are going a step further to include people with special needs and disabilities known as outliers.

\section{User-Centered Approach: Outliers in Inclusive Design:}

User-centered approach to inclusive design involves using outliers to identify distinct needs of end users in extreme situations such as people with special needs and disabilities. Interdisciplinary design teams consult with outliers because they provide insight that help inspire opportunities for effective, innovative and creative outcomes, which is useful at the initial stage of design.

The following section presents an example of a contemporary design consultancy firm (Smart Design) that uses outliers at the initial stage of design development to inspire effectiveness and ease of use in design projects.

\section{Dan Formosa: OXO good grip:}

A contemporary example of design projects developed with outliers at the initial stage is the OXO good grip, a product line of kitchen tools. This product line was designed and developed by an American-based design consultant Dan Formosa, who co-founded Smart Design (Greene, 2010).

The aim of developing the OXO good grip product was to cater to a wider range of end users. This includes those with special needs and disabilities such as arthritis, which is a joint disease that affects the hand, hindering its effective use when handling day to day activities.

The OXO good grip product was designed and developed by first addressing the needs of outliers (i.e. people with special needs), as well as identifying areas, that could inspire 
innovation, efficiency. This research process of addressing and identifying areas of need provides insights into the creation of efficient and functional products that is not only aesthetically pleasing but fits the purpose for its creation. In this case the outliers was a specific end user with arthritis. The need for a better and more comfortable grip on kitchen tools may have been identified in this way, but formed the basis for a more inclusive and generally more comfortable and effective solution.

Dan Formosa's work ethics focuses on Universal design, which involves designing for a wider range of end user, involving outliers (people with special needs and disabilities), researching their needs and generating insights that will enable the development of effective, functional and easy to use products (Greene, 2010).

\section{Interdisciplinary Collaboration Practice}

Professional interdisciplinary teams made up of architects, designers, social scientists and environmental psychologists are making efforts to become ambassadors of inclusive design with a focus on social inclusion and participation. These initiatives strive to give end-users some level of control over their built environments. Highlighted below are contributions such interdisciplinary ambassadors have made:

- An American interdisciplinary team of design professionals known as the Community Design Center Movement is at the forefront of delivering free design consultancy to endusers (Sanoff, 2000).

- Teams based in Denmark and the Netherlands have formed committees that incorporate end-user participation at different stages of design development (Habraken, 1973; McCamant \& Durrett, 1994). 
- Research and design collaboration among design professionals, human factors and ergonomic scientists (HFE) have resulted in an improvement in human performance in the built environment (Wolski et al., 2000).

- Designers and social scientists now collaborate to increase knowledge of the relationship between human behavior and the built environment (Hall, 1969; Sommer, 1969).

\subsubsection{Contemporary Approaches to Wayfinding Design: Evidence in Practice}

Designers are approaching wayfinding in creative ways, going beyond simply using wayfinding signs to direct end-users. This includes incorporating branding as a wayfinding technique, which gives meaning and identity to the built environment. Creative approaches also involve the use of color coding techniques, images and graphics to create identity and communicate wayfinding information clearly to end-users.

The following section presents an example of a specific contemporary approach by Teresa Sapey that has been widely noted to provide new forms of effective wayfinding solutions for end users. The aim of this section is to show how new creative approaches could influence campus design and wayfinding, for example at Carleton University.

\subsubsection{Teresa Sapey: Car Park Puerta America Hotel}

A contemporary wayfinding project of interest is the parking garage at Puerta America Hotel, located in Madrid, Spain, and designed by the Madrid-based architect and designer Teresa Sapey. The main purpose in designing this two-storey parking garage was to increase safety and user-friendliness. Sapey achieved this by combining lights, graphics, colour and text in specific proportions, using subtle text and symbols painted on the garage wall to direct endusers when driving or parking (See figure 7). 
The hotel itself was designed and developed by an interdisciplinary team made up of nineteen architects, designers and artist Paul Eluard (Nowacek, 2005). Sapey took inspiration from Eluard, as can be seen in the parking garage design, which is a creative combination of art and design. In addition to providing enhanced wayfinding information and promoting safety, Sapey's aim was also, therefore, to create a space that meets end user's needs as well as reduce stress (Nowacek, 2005; Ingram, 2010). Sapey’s work ethic includes creating relationships with clients, researching user needs (both the client and hotel visitors) and collaborating with diverse people from different interdisciplinary backgrounds (from architecture and design to art and literature) (Nowacek, 2005; Ingram, 2010).
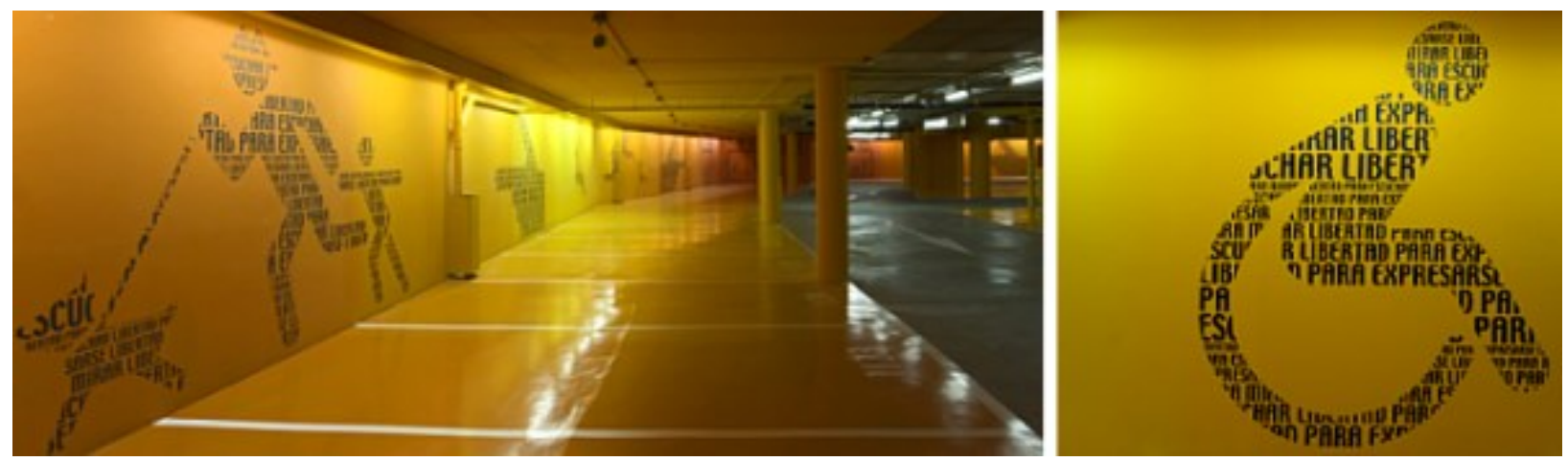

Figure 7. Car Park Puerta America Hotel by Teresa Sapey (Nowacek, 2005).

\subsubsection{Best Practice}

In order to guide organizations that are embarking on new construction or a new wayfinding exercise, best practices have been developed (Kernohan et al., 1992; Gibson, 2009). These typically include a set of processes that are followed in order to guide the eventual outcome towards effectiveness and functional usability. To achieve this, the designer must observe and implement certain key processes, including defining the project, providing support and funding, setting up committees, organising design reviews with the aim of establishing policies 
and finally working with standards organisations to ensure compliance with regulations. The following paragraphs describe the typical stages of a project, so as to outline and clarify the process that would normally be used in a university to address projects involving wayfinding.

\section{Project Definition and Briefs}

Project definition is the first stage of wayfinding projects. This stage involves determining the scope of the project by making inquiries about wayfinding issues, needs and the implementation process. This process can benefits from consultation with spatial design professionals such as architects, industrial designers and urban planners. Their input complements personal fieldwork and research in determining the scope of the project and constructing a proposal establishing the guidelines that will serve as a benchmark for the final project (Kernohan et al., 1992; Gibson, 2009).

\section{Support and Funding}

After the proposal has been developed, the designer must ensure the support of the organisation's management. If the design modifies an existing built environment, this dialogue will focus on existing problems. If, however, it is a new project, the dialogue will be in response to needs expressed by the management (Kernohan et al., 1992). At this stage, careful financial planning, budgeting and funding are crucial. When funds are not immediately available, other sources, such as fund-raising events, can help supplement the initial budget. 


\section{$\underline{\text { Project Committee Members }}$}

Best practices dictate the constitution of a committee to steer the project. Ideally the project committee includes representatives from three distinct groups: the organization's management team, stakeholders and the wayfinding committee.

The management team has decision-making authority over the project, and dictates the progress of the project. The director of facility management and planning is an example of a likely management team member (Kernohan et al., 1992; Gibson, 2009).

Stakeholders provide insight and feedback during the design process, and might address issues the organisation faces. Ideally, stakeholders speak to the experience and needs of endusers. In the context of projects on university campuses, possible stakeholders include university departments such as student support services, campus security and student affairs.

The wayfinding committee is comprised of individuals or groups who act as facilitators and are interdisciplinary in their expertise, meaning that they ensure that dialogue involves diverse perspectives. They work as design interlocutors between end-users and the management team (Kernohan et al. 1992; Gibson, 2009). Examples of wayfinding committee members are design and communication representatives, facility managers and design consultants who specialize in wayfinding research (Kernohan et al., 1992; Gibson, 2009).

\section{Design Review Process}

Designers often meet with all interest groups and stakeholders at the early stage of design development. The end-users in this meeting are individuals or groups representing different sections of the community. An educational organisation, for example, will typically draw its end-users drawn from different departments of the institution. 


\section{$\underline{\text { Establishing Strategy and Policies }}$}

The purpose of meetings of the management team, stakeholders and the wayfinding committee is to generate a dialogue on wayfinding issues pertaining to the campus or community. This dialogue also relies on interviews conducted with the aim of gaining information about wayfinding issues faced by end-users. The chief goal of the dialogue, however, is to develop purposeful strategies. After these discussions, the designer conducts a series of tests, including research analysis, to determine how the information provided and the ideas generated can be used to establish policies and strategies.

The next stage in planning is the buy-in process, which involves a meeting between the designer and key stakeholders (the organisation's representatives) at which the designer presents the proposal using media such as three-dimensional drawings, sketches and other professional presentation media. After the key stakeholders give approval, representatives of the organisation staff are invited to a briefing to inform them of the final design and strategies for implementation.

The designer must also consult with the necessary bodies in charge of codes and requirements. This helps ensure that the final wayfinding design outcome meets the required standards, e.g., building and accessibility standards and fire standards. It should be noted that this is an ongoing process that involves repeated iterations in which some design proposals are rejected. However, persistence pays off in the long run (Gibson, 2009).

\section{$\underline{\text { Standards and Requirements }}$}

Several sets of standards regulate wayfinding practices. In Ontario, these include the terms of the Accessibility for Ontarians with Disability Act (AODA) and local sign standards, which include regulations for emergencies such as fire. The AODA regulations were introduced 
in 2005 with the aim of making Ontario accessible to people with various disabilities, especially in areas relating to spatial communication and the built environment (AODA Regulation, 2005). These regulations require designers to ensure the rights of people with disabilities and understand the issues that they face daily, especially when navigating complex environments (Brooks \& Kleiner, 2003).

Some organisations also have their own internal standards that serve as guidelines to address issues involving wayfinding (Kovacs \& Gordon, 2010; Gibson, 2009). Internal guidelines typically regulate issues such as size, position, location, letter style and attributes such as contrast, tactile signs (Gibson, 2009; Dischinger, 2012; Stempler, 2013) and specialized accessibility symbols (Ben-Moshe, 2007).

Particular guidelines for emergency signage are of vital importance. Special requirements call for the installation of graphic information systems and spatial features such as sign positioning and egress at stairwells and elevators in case of fire and other life- threatening emergencies. Furthermore, it is important to consult regulation specialists at the city, provincial and federal levels to obtain current information about relevant standards and regulations (Gibson, 2009).

\subsection{Evidence-Based Design Research in Practice:}

This as the name implies, is an approach to design research that involves the use of tested and proven research methods that have been applied in similar design situations. These serve as primary human-centered evidences (data) and typically include interviews, surveys and site visits. This research approach involves all stakeholders and can be incorporated at any stage of the design process (Martins \& Hanington, 2012). 


\section{Design Participation}

Design participation involves representatives of different stakeholder groups in the development process (Lawrence, 1981; Gibson, 2009). This is a feature of most development processes, especially spatial design processes. For example, low-income end-users in low-cost housing projects are normally consulted (Turner 1976; Alexander 1985), as design experts have realized that end-users help produce better designs. Engaging end-users typically involves activities such as stakeholder meetings and participation by providing information to design committee members so that they can make informed decisions. Design committee members are thus better able to make informed decisions that will best serve end-users.

\subsubsection{End-User Involvement}

It is evident that there is value in consulting with end-users in the design process (Kernohan et al., 1992). However, for effective consultation, the role of the end-user should be clearly defined. End-users are individuals or groups that are legally allowed to use a facility for the purpose for which it was designed. In an academic setting, for instance, this would include students. The term of use could be long term or short term (Kernohan et al., 1992). The advantage of consulting end-users is to generate information through evaluation and feedback; this helps to identify what works and what does not. Information from end-users determines the need for improvement of existing facilities or establishment of standards for new developments (Kernohan et al., 1992). End-user participation also enhances social awareness: knowledge shared during the facility evaluation process highlights the issues and developmental processes involved.

The evaluation process precedes implementation and engages three sets of individuals or groups with distinct roles (Kernohan et al., 1992): managers, facilitators and end-users. 
Managers are directly concerned with development activities, and they, approve and authorise evaluations. The facilitators, who in this case could be designers, are interlocutors who mediate between end-users and managers. Their roles include initiating the evaluation that allows for dialogue and shared perspectives with end-users on a design project (Kernohan et al., 1992). The end-users, who might be drawn from different groups, provide evaluations of the design project. In addition, it is important to understand that universal design principles require the identification of people with special needs in order to make the design as inclusive as possible. At the same time the notion of outliers means that specific design insights can be gained from users who have identified distinct problems.

\subsubsection{Facility/Infrastructure Evaluation}

Facility/infrastructure evaluation occurs either at the design or completion stage of a spatial design project; it can also be called Post-Occupancy Evaluation (POE) (Preiser, 1995). POE refers to a systematic tool used by facility managers to investigate the efficiency and performance of a building. It involves evaluating existing facilities and prototypes of new facilities in order to develop guidelines that can be used as a benchmark for similar design projects (Kantrowitz \& Nordbaus, 1980; Preiser, 1995; Vischer, 2009).

POE has been in existence for almost 40 years and has been proven to be an effective knowledge-gathering process (Preiser, 1995). POE can take several forms, but for the purpose of this study, it includes an evidenced-based knowledge-gathering process that allows for openended dialogue, expression of like or dislike for a particular facility and a sematic scale used to ascertain the extremes of certain criteria in a facility that could affect the end-user (Kantrowitz \& Nordbaus, 1980; Preiser, 1995; Vischer, 2009; Hassanain 2007). POE processes have been used in many different settings, including public institutions (Riley, 2010; McGrath and Horton, 
2011) and students' facilities (Hassanain, 2007). For instance, Hassanain (2007) developed a POE system to assess the interior environmental quality of student housing facilities at a Saudi Arabian University. He developed this system in order to gauge the effectiveness of the decisions made during the design process by considering them against the actual performance of the facility. The system involved a user satisfaction survey to obtain feedback on students' experience and perception of their interior environments (Hassanain, 2007).

\subsection{Literature Summary}

A review of research literature in areas connected to complex public environments, psychological and physical aspects and evidence-based participatory design methods, discussed in this chapter, serves as the basis for this study.

According to the literature investigated, inclusive design has come to be emphasised in the development of spatial design components and communication features for wayfinding and accessibility in complex environments. These features must also incorporate planning for people with disabilities in emergencies and extreme situations. Wayfinding and accessibility issues in complex public environments are strongly associated with the functional usability and significance of spatial design components and communication features.

Users of these complex environments adopt cognitive and perceptive processes for better awareness and understanding of their surroundings. While most users experience these processes in similar ways, variation can occur, especially for people with disabilities and in emergency evacuations. Inclusive planning must therefore take into consideration factors such as personalised strategies, individual differences and the nature of disabilities among end-users.

Emergency conditions and disability are a reality for the built environments, and require design and non-design professional stakeholders to re-think wayfinding and accessibility 
strategies in order to build a safe and inclusive environment. Attention to these factors also encourages social participation among end-users by engaging them in initiatives and assessments that will help improve existing and develop new projects. 


\section{CHAPTER 3}

METHODS

\subsection{Introduction}

The purpose of this research was to gain insight into a wayfinding development process. The qualitative research approach and framework is this case study, utilizes disparate methods of data collection. Specifically the study explores wayfinding at a university campus by examining and analyzing many different separate stakeholders' viewpoints. Carleton University in Ottawa was the site for the exploration; this site includes complex spatial structures, multicultural end-users and the strategic goal of being an accessible and inclusive institution. Participants, who doubled as stakeholders, were grouped into three main categories:

Stakeholder 1 (design consultants), Stakeholder 2 (organisation staff), and Stakeholder 3 (student end-users). Stakeholders in groups 1 and 2 participated in the semi-structured interview and stakeholders in group 3 participated in the open-ended online survey.

Issues were addressed from a broader perspective, such as the contextual and strategic aspects that served as variables for investigation, interpretation and analysis (Creswell, 1998). In considering these variables, the researcher accumulated multiple sources of data as evidences from semi-structured interview, open-ended survey questions and archival document analysis. Triangulation helped provide meaningful insights that provide answers to the research questions (Creswell, 1998).

This study focused on the 'how?' and 'what?' lines of inquiry, with the intent of understanding participants' experiences and perceptions of their travel activities around campus. This broadened the scope of the study by providing insight into the significance participants attach to accessibility and wayfinding. The overarching research question (RQ) was: How can the wayfinding design process be improved in University campuses? 
Following this overarching question were sub-questions (SQ) that formed the basis of inquiry for the research methods used (i.e., interview questions, open-ended survey questions and archival document inquiry) (Miles \& Huberman, 1994). These sub-questions included:

SQ1: What best practices are involved in the wayfinding design process at Carleton?

SQ2: How can these best practices for the wayfinding design process be improved at Carleton University?

This chapter presents the methods used in the collection and analysis of the qualitative data. The structure of the chapter corresponds to the way data was collected and grouped into themes and categories for better organisation, analysis and interpretation. Insights gained through the research methods mentioned above were intended to provide answers to the research questions. These insights were drawn by exploring interdisciplinary processes as well as inclusive approaches to the design and development of wayfinding and accessibility systems in complex public environments.

\subsection{Evidence Source 1: Semi -Structured interview}

\subsubsection{Participants}

A total of eight participants in different professional positions were interviewed. These positions included industrial designers, a psychologist, space management and planning officials, a signage consultant, as well as a community liaison officer for safety, and finally representatives of people with disabilities and a campus residence building service representative. These stakeholders have distinguished themselves in various academic and professional backgrounds and were interviewed in two categories (see Table 1). 


\section{$\underline{\text { Category } 1}$}

Category 1 refers to professional stakeholders or design consultants who have a record of accomplishment in design, especially in the areas of spatial design, environmental planning and wayfinding design in new and existing complex structures in Ottawa, elsewhere in Canada and beyond. The portfolios presented on their respective websites indicate years of experience and competence in dealing with spatial design, planning and wayfinding issues. These are, therefore, experts in the field of wayfinding design.

\section{$\underline{\text { Category } 2}$}

These are Carleton University staff members with a track record of experience in their respective departments, especially in the areas of spatial design project development, design strategy, policy making, accessibility and post-occupancy evaluation.

\begin{tabular}{|c|c|c|c|}
\hline \multicolumn{4}{|c|}{ Interview Participants } \\
\hline \multicolumn{4}{|c|}{ Experts (Category 1) } \\
\hline Name & Designation & Company/Department & Location \\
\hline Stewart Bailey & Principal Designer & Intu Design & Ottawa \\
\hline Janet Bewell & $\begin{array}{l}\text { Senior Experience Architect } \\
\text { and Psychologist }\end{array}$ & Akendi & Ottawa/UK \\
\hline \multicolumn{4}{|c|}{ Carleton University staff members (Category 2) } \\
\hline Dean Mellway & Disabilities Coordinator & \multirow{2}{*}{$\begin{array}{l}\text { Paul Menton Center } \\
\text { (serving people with } \\
\text { disabilities) }\end{array}$} & \multirow[t]{6}{*}{ Ottawa } \\
\hline Somei Tam & $\begin{array}{l}\text { Learning } \\
\text { Specialist/Disability } \\
\text { Advisor }\end{array}$ & & \\
\hline Matthew Cole & $\begin{array}{l}\text { Attendant Services } \\
\text { Co-ordinator }\end{array}$ & $\begin{array}{l}\text { Campus Residence } \\
\text { Building Service }\end{array}$ & \\
\hline Anne Richards & $\begin{array}{l}\text { Assistant Director, Space } \\
\text { Management and Capital } \\
\text { Planning }\end{array}$ & \multirow[t]{2}{*}{$\begin{array}{l}\text { Space Management and } \\
\text { Planning/Signage Service }\end{array}$} & \\
\hline John Algie & Signage Consultant & & \\
\hline $\begin{array}{l}\text { Mark } \\
\text { Hargreaves }\end{array}$ & Community Liaison Officer & $\begin{array}{l}\text { Department of University } \\
\text { Safety }\end{array}$ & \\
\hline
\end{tabular}

Table 1. Interview Participants 


\subsubsection{Setting}

The semi-structured interview was held at Carleton University, the case study site. This site was chosen because it is easily accessible to the participants as a result of their relationship with the institution, either as staff members or as alumni of the institution. All of the participating staff members opted for a one-on-one interview in their respective offices. One of the expert participants, Stewart Bailey of Intu Design, opted to have the interview at Carleton University's School of Industrial Design Master's Studio. Janet Bewell of Akendi, who was in the United Kingdom and was therefore not available for an in-person interview, opted to have the interview via Skype, an online audiovisual telecommunication service.

\subsubsection{Data Collection Procedure}

Prior to the interview day, the researcher sent an introductory email to the interview participants. The email contained information about the researcher's intentions, research study details and duration (see Appendix A). Each of the expert and staff interview participants responded selecting a day and time to be interviewed. Interviews were conducted between March 28 and April 3, and ranged from 30 to 60 minutes, depending on the depth of information discussed and the work schedule of the participant.

At each interview, the participant was presented with a consent form that had been reviewed and approved by Carleton University's Research Ethics Board (Appendix B). This document included the purpose of the study, the tasks involved and the duration of the interview. The document also highlighted the option for anonymity and confidentiality, consent to voluntary participation, contact information of the Research Ethics Board and the researcher, as well as the right to withdraw from participating in the study. Having reviewed this document with the participant, the researcher went ahead to ask the prepared questions (see Appendix C). 
Questions were open-ended, which allowed for in-depth discussions and further clarification of participants' insights when their initial responses were not clear to the researcher. The interview session was recorded using a mobile electronic sound recorder, which allowed the researcher to focus on the interviewee and the ensuing conversation, rather than on note-taking.

\subsubsection{Data Analysis}

After the data collection process, the audio-recorded interview from each participant was transcribed and less important information was filtered out. This method helped the researcher identify relevant insights. As insights emerged, they were grouped and organised into categories and themes, using Microsoft excel spreadsheet and an affinity diagram method. This formed the structure of the affinity diagram in chapter 4 . Some quotations from the transcriptions were used as evidence to support the general insights that emerged from the interviews.

\subsection{Evidence Source 2: Survey (Online)}

\subsubsection{Participants}

The second source of evidence was a survey conducted online. A total of ten participants participated in the survey. These participants were Carleton students.

\subsubsection{Setting}

A Canadian-based online software, Fluid Surveys, was used for the survey because of its flexibility, intuitiveness and availability. Its location in Canada made it possible to prevent ethical and data privacy issues that may arise when using foreign servers. The advantage of using this medium over a paper-based medium was its ubiquitous nature and universal reach, 
which makes it accessible anywhere at any time. This made it easy for participants to respond at their convenience.

\subsubsection{Data Collection Procedure}

As with the semi-structured interview, an introductory email (with a link to the Fluid Survey page) and a consent form was sent to 10 students at Carleton University. Recipients of this email were also encouraged to distribute information about the survey to their colleagues (see appendix D and E). Recipients were asked to read the attached consent form and indicate whether they agreed or declined to participate in the survey. The introductory email contained the study intent, the study procedure and the researcher's contact information. Survey questions were broken down into three sections: section $\mathrm{A}, \mathrm{B}$ and $\mathrm{C}$, in a sequential format (see appendix F). Section A was comprised of multiple-choice questions based on end-user perspectives. Section B consisted of a five-point semantic scaling question with open-ended text box for further explanations of participants' perceptions of wayfinding characteristics and corresponding activities at the case study site. Section $\mathrm{C}$ had open-ended questions on end-user wayfinding experiences on Carleton University campus, with text boxes provided for responses.

\subsubsection{Data Analysis}

The Fluid Survey's intuitive nature made it easy for data to be collated and organised. The software recorded every survey question entry and automatically collated the data into an organised format. The multiple-choice questions were analysed and represented by bar graphs. These bar graphs highlighted the responses of each participant.

The five-point semantic scaling questions were arranged in a format that showed the total responses to each question, participant rating mean score and standard deviation. The five-point 
semantic rating was used specifically to show the relationship between the insights derived from interviewing the experts and staff on the one hand and the students' satisfaction with their environments on the other hand.

\subsection{Ethics}

The protocol for this study was reviewed and cleared by the Carleton University Research Ethics Board. The Board concluded that the semi-structured interview and survey met the ethics review standards. In deciding that the methods met ethical standards, the Board found that the protocol used was of minimal risk, as there were neither discriminatory questions nor actions that could cause harm or discomfort to the participants. In addition, participants were provided with the option of anonymity and confidentiality, consent to voluntary participation, as well as the right to withdraw from the study (see appendices B and E). Participants were also informed of the objectives of the study and task activities.

\subsection{Evidence Source 3: Archival Document Analysis}

Qualitative evidence derived from archival document analyses was used to complement the interview and survey data, in order to create a triangulation of perspectives.

\subsubsection{Setting}

Documents were retrieved from the Carleton University website (www.carleton.ca). This provided information on the institution's policies and strategies around accessibility, as well as design and spatial development. These electronic documents were available because of the university's policy of making information readily accessible and available (Carleton University Strategic Integrated Plan, 2013). Moreover, they were used with the permission of 
participating departments. The information obtained from these documents was in line with the categories and themes that emerged in the Evidence Source 1 (see Appendix H for a bibliography of retrieved Documents).

\subsubsection{Data Collection and Analysis}

The researcher accessed Carleton University's website and extracted both HTML and PDF documents with permission from the various departments that were represented in the interview phase of this study (see section 3.5.1). The content of the documents was categorised according to the insights generated from the previous research and the evidence discussed in this chapter (see Appendix H). The researcher also used keywords such as design, strategy, accessibility and other keywords and themes identified in the previous methods to draw relevant insights from the documents. 


\section{CHAPTER 4 \\ RESULTS}

\subsection{Introduction}

This chapter presents the results of the qualitative data collected through the three research methods discussed in Chapter Three: semi-structured interviews, open-ended survey questions and archival document analysis. This chapter is structured according to the way the data was collected and is grouped into themes and categories for better organisation, analysis and interpretation. In addition, participants involved in the research were divided into three categories: Stakeholder 1 (design consultants), and Stakeholder 2 (organisation staff who participated in the semi-structured interview), and Stakeholder 3 (student end-users who participated in the open-ended survey).

\subsection{Evidence Source 1: Semi-Structured Interview}

The interview data was collected at Carleton University in Ottawa, with stakeholder 1 and 2 categories as participants (see Table 1). The data retrieved from the interviews was transcribed into categories and themes (see Appendix J). The major concepts that emerged were organised into four aspects, namely contextual, strategic, interdisciplinary and social participation, as shown in Figure 8 below.
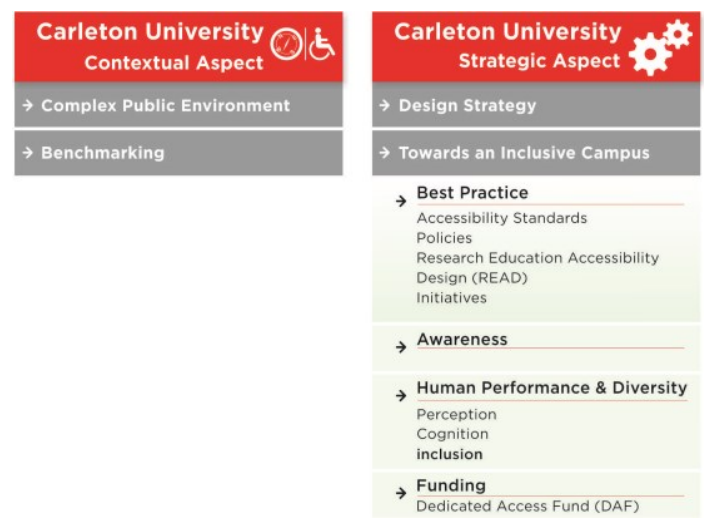

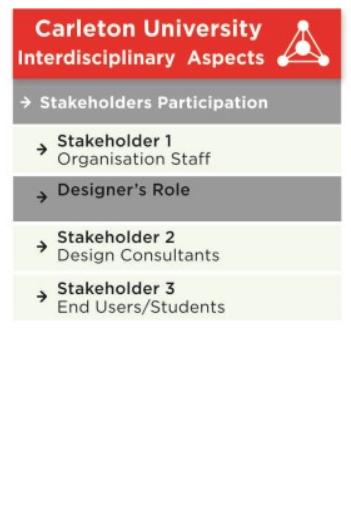

Carleton University

Social Participation

$\rightarrow$ End-User Involvement

$\rightarrow$ Infrastructure/Facility Evaluation

Figure 8. Affinity diagram showing categories and themes (Oyelola, 2014) 
The first aspect examined was the context of Carleton University and its significance in the Ottawa community. The second aspect examined strategy adoption and the development process towards the goal of an inclusive environment, covering themes such as best practices, awareness, funding, human performance and diversity. The third category examined interdisciplinary aspects, which involves the stakeholders and the role of design. The fourth aspect, social participation, presents the end-users' involvement and infrastructure/facility evaluation.

\subsubsection{Carleton University (Contextual Aspects)}

\section{Complex Structure}

Most of the participants spoke about the complex nature of the campus in one way or another, in terms of the layout, topography, floor levels, and environmental legibility (see Appendix $\mathrm{J}$ for interview quotations on converging categories and themes).

Layout: The design respondent Stewart Bailey of Intu Design pointed out that getting lost in an environment such as Carleton University could be problematic, especially for organisations that have staff who direct visitors to their destination, because a properly designed building will require little or no effort in directing people. Anne Richards of Space Management and Planning at Carleton University noted that the campus is broken down into different zones, namely academic (west and east), administrative (north and south) and residential. Also, Dean Mellway of Carleton's Research, Education, Accessibility and Design (READ) Initiative emphasised how big the campus is and how long it might take disabled and able people alike to learn the layout and adjust to navigating their way through the campus. 
Topography: Dean Mellway explained that wayfinding difficulties exist on campus because of its large size and its geographical position being partly on a highland, has in turn created a steep incline, which is difficult for anyone using a wheelchair to manoeuvre.

Floor level: In addition to the steep incline due to the site's topography, some of the floor levels start at the tunnel level while others start from the ground level. Anne Richards explained that the Space Management and Capital Planning department of the university decided on a case-by-case basis whether the floor level should start at the tunnel or the ground floor. This according to Anne Richard is achieved by starting the floor level numbering from the tunnel level in order to ensure clarity.

Environmental Legibility: John Algie, a signage consultant with the Space Management and Capital Planning department on campus, explained that signage types used by Carleton are easy to identify in any situation, day or night. He gave the example of exterior signs with reflectors that are responsive to vehicular lights.

\section{Extreme Conditions}

Participants also raised concerns about extreme conditions such as fire and other emergencies and barriers to mobility for people with disabilities (see Appendix $\mathrm{J}$ for interview quotations on extreme conditions).

Fire emergencies: Matthew Cole of Campus Residence Building Services and Mark Hargreaves of the Department of University Safety highlighted the need for emergency procedures, especially in buildings of more than four levels. They also commented on the need for policies that encourage fire drills and immediate responses to evacuation orders when the fire alarm goes off, in order to prevent injury in potentially panicked situations. 
Barriers to mobility: Barriers to accessibility and mobility highlighted by Dean Mellway, include the effect of weather on the infrastructure, particularly the pathways, since snow and ice can be a barrier to people with physical disabilities. Frequent construction and renovation around campus was cited as a source of problems for people with visual disabilities. Mellway also commented on the absence of proper lighting and sensory cues for people with visual impairment. Such sensory cues could include tactile signs for room numbering and floor indicator buttons, and audible announcement systems in elevators.

\section{Benchmarking}

Mathew Cole, the Campus Residence Building Service representative, said, "I think we are ahead as a university, people are encouraging us to do more." This statement highlights the need to create a sense of belonging among the campus community by responding to complaints made by end-users. This, according to Cole, will lead to improvements in accessibility across the University.

\subsubsection{Carleton University (Strategic Aspects)}

\section{$\underline{\text { Design Strategies }}$}

Anne Richards, the Assistant Director of Space Management and Capital Planning department commented on strategies that could be applied to the site layout to increase environmental legibility (see Appendix $\mathrm{J}$ for interview quotations on design strategies).

Layout: Strategies highlighted for the campus layout included creating alternative routes for people with disabilities. Dean Mellway of Carleton's Research, Education, Accessibility and Design (READ) Initiative noted: "You can find alternative routes to avoid bad spots." 
Environmental legibility: Strategies highlighted in this category included signs, accessibility features and visual cues. According to Matthew Cole, Dean Mellway and Stewart Balley, these features make an environment legible and accessible.

Signs and maps: Somei Tam and Matthew Cole, representatives of the campus community, commented on the importance of informative signs on the physical floor level and room numberings system. They also stressed the usefulness of having the right size, colour contrast, and font size on signs to ease viewing by physically and visually impaired individuals.

Visual cues: Matthew Cole and Dean Mellway also commented on the need for visual cues to be intuitive, functional and accessible by considering certain criteria such as legibility at building entrances, Braille on signage and elevator buttons, as well as warning signs placed intuitively to avert injury where there is a hazard.

\section{Best Practice: Standards, Policies and Initiatives:}

The semi-structured interview and archival document analysis provided insights into the best practices at Carleton University. The result of these two research methods revealed the experiences that respondents have with Carleton University standards, policies, initiatives, human performance and diversity as well as funding. The insights also focused on inclusive design at Carleton University especially for people with disabilities.

Somei Tam strongly advocated for adherence to inclusion and accessibility in spatial design development and is delighted at the large amount of research in this area. In addition, she expressed delight at including people with different types of disabilities in the research.

Dean Mellway of Carleton's Research, Education, Accessibility and Design (READ) Initiative explained that the READ initiative seeks to identify deficiencies in policies regarding disabilities and to determine how they can be addressed. Anne Richards, the Space Management 
and Capital Planning Director, also noted that policies regarding accessibility and wayfinding are designed to address immediate issues and reinforce existing standards. Anne Richards further mentioned that her department reviews every new construction to check for compliance with building and accessibility standards. Matthew Cole and John Algie stated that there is constant evolution in wayfinding standards, and these standards adjust to increase inclusivity. For instance, developing standards encourage better lighting and signage systems for people with low vision or impairments, in addition to existing standards that call for a certain font size and colour contrast on signs.

Awareness: Awareness is another crucial factor in developing an inclusive campus, as both Dean Mellway and Somei Tam noted. They stressed the need for designers and key stakeholders to be aware of how design influences individuals by being empathetic. Empathy allows designers and key stakeholders to view things from the perspective of the end-user. Somei Tam suggested that one way of achieving this is to go through a series of simulations to depict different human conditions.

Human Performance and Diversity: Dean Mellway also highlighted the relevance of human performance and diversity in promoting an inclusive campus. He indicated factors such as route learning, the cognitive process and individual differences that people with disabilities face, especially people with visual and physical disabilities.

Funding: Dean Mellway explained that there is a dedicated access fund (DAF) available to help provide the resources required to respond to individual issues that may arise because of inaccessibility around campus. Janet Bewell of Akendi also agreed on the need for budgeting and funding in order to achieve inclusivity; as she said, "if you have a great idea without a budget, it is not going to happen." 


\subsubsection{Carleton University (Interdisciplinary Aspects)}

\section{Stakeholder Participation}

As stated earlier, three categories of stakeholders participated in this study: Stakeholder 1 (design consultants), Stakeholder 2 (organisation staff) and Stakeholder 3 (student end-users). Members of each category have a role to play in the wayfinding design process. However, for the purpose of this case study, stakeholders were categorised according to their level of involvement (see Appendix J for interview quotations relating to stakeholder participation).

Organisation Staff: The Space Management and Capital Planning department of Carleton University is the key department that influences wayfinding design decisions. This department is directly in charge of policies, standards and implementation concerning spatial planning, facility and infrastructure management, as well as spatial information, which includes signage and maps. They have a signage and wayfinding committee that involves a stakeholder from every department on campus. The purpose of the committee is to discuss project budgets, review and approval when embarking on wayfinding projects on the campus. Occasionally the committee seeks the opinion and advice of committee members such as Matthew Cole and Dean Mellway on matters relating to accessibility and barrier-free installations before construction. However, not all of the committee members consulted attend regularly.

\section{Designers' Role}

During interviews, the researcher tried to identify areas where designers can be relevant in solving wayfinding and accessibility issues in complex environments such as Carleton University. However, there was no clear response in that regard. During the interview with stakeholders 1 and 2 (design experts and staff members respectively), respondents made some points that indicated the potential direction designers could assume. 
Design Consultants: Design effectiveness and function usability: Anne Richards and John Aglie highlighted that in extreme situations such as emergencies, it is not enough to have signage everywhere. However the effectiveness of the signage when directing people is what measures success. Stewart Bailey, a principal designer and wayfinding specialist at Intu Design, advised involving a wayfinding design specialist at the early stage of spatial design and planning projects. He also cautioned that applying a do-it-yourself approach does not work. Furthermore, Bewell stressed the need for designers to understand the end-user needs of multiple groups. She pointed out that this can be achieved by acting as a design interlocutor, gaining insights into user motivation, perceptions and goals, in addition to the aesthetics of the project.

\subsubsection{Carleton University (Social Participation)}

All the participants agreed that social participation becomes relevant when the three stakeholder categories work in unison. Organisation staff members, especially from the Space Management and Capital Planning department of the University, review the standards, policies and implementation of spatial design and planning projects. This department also sets up a committee to engage in dialogue with other organisational stakeholders. The design consultants play a role in understanding end-user needs of multiple groups by gaining insights into their motivation, goals and most importantly perceptions. In light of this, the third stakeholder category (end-users) became especially relevant, considering that they are most affected by the outcomes of the decisions made by the committee and the design consultants. Participants in these category included departmental representatives of campus safety, residence building service and students with and without various disabilities. 
End-user involvement: John Aglie and Anne Richards of the Space Management and Capital Planning department stated that they consult with end-users because they are more knowledgeable with regard to their individual experiences.

Infrastructure/Facility Evaluation: In addition to end-users' knowledge and experience, all the stakeholders agreed that in addition to the pre-occupancy committee review, postoccupancy evaluation is necessary to evaluate existing facilities. This enables design and organisation stakeholders to gain insight into end-user satisfaction and perceptions of the facility or infrastructure.

\subsection{Evidence Source 2: Survey (Online)}

The data from the semi-structured interviews and the supporting archival documents shed light on the need for an accessible and inclusive environment that incorporates best practices, awareness and funding. However, drawing insight from the end-users' perspective and perceptions of the case study site in general adds to the knowledge base of this research. The survey was presented in three sections, in a sequential format (see appendix F). Section A had questions based on end-user campus perspectives (see Figure 9). Section B had questions based on participants' perception of wayfinding characteristics and corresponding activities at the case study site. Section $\mathrm{C}$ had questions on the end-user wayfinding experience on Campus.

\section{$\underline{\text { Section } A}$}

More than half of the end-users $(60 \%)$ who participated in the survey have spent up to a year or more on campus, while fewer than half (40\%) have spent six months or more on campus. In addition to this, $80 \%$ of the end-users who participated are visually oriented, 
meaning they respond based on visual information from the environment. Those who are selfdirected and curious represented about $10 \%$ each respectively.

\section{Complex Nature of Spatial Design}

The participants' perception of the spatial design component and accessibility system around campus was not encouraging, as $40 \%$ of the participants reported being indifferent and another $40 \%$ reported dissatisfaction. Only $20 \%$ of respondents indicated satisfaction. Reasons given for the level of dissatisfaction reflected the complex nature of the university layout, the site topography and incongruent floor levels, as well as a lack of environmental legibility (see appendix G for details of end-users' comments Since courses are scheduled within 10 minutes

of each, students were asked how long it would take to get from one class to another. $40 \%$ spent less that 10 minutes with $40 \%$ saying it took them just about 10 minutes, and $20 \%$ of students indicating that it can take more than ten minutes (see Figure 9 below).

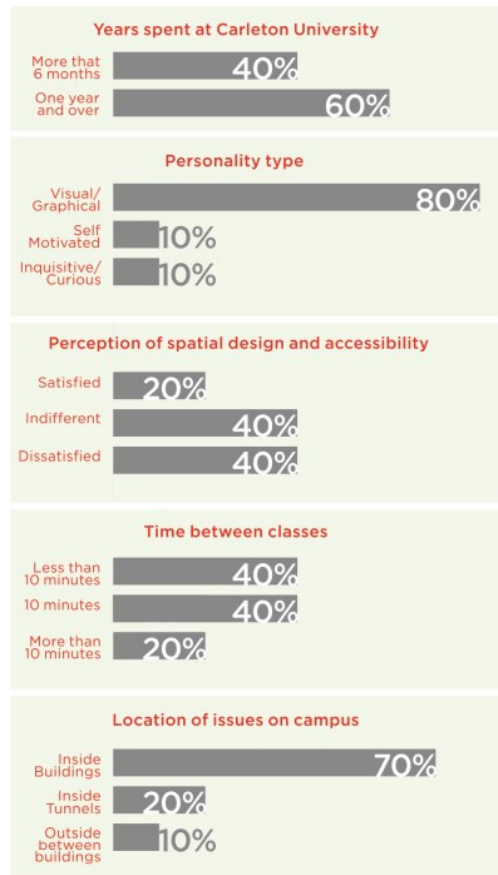

Figure 9. End-users' responses to section A of the survey (Oyelola, 2014) 
In terms of asking the students what areas of campus were more difficult to navigate, they had to choose between "inside buildings, "inside tunnels or outside buildings." 70 percent of respondents indicate that it is more challenging to access and navigate indoors than in the tunnels, while 20 percent find the tunnels the most challenging location on campus, and 20 percent cite the exterior environments as the most challenging (reasons respondents gave are highlighted in appendix G).

\section{$\underline{\text { Section B }}$}

This section contains the semantic differential scale. Its purpose was to generate insight into end-users' perceptions of the Carleton university campus. The perceptions involved evaluating the spatial characteristics and corresponding activities on a scale of 1 to 5 , using a method adopted by Hassanain (2007). For instance, respondents will evaluate the perception of the spatial characteristics with a value of one for extremely relevant and five for not relevant at all. Likewise, the perception of the spatial activities will be given a value of one for easy and five for difficult.

\section{Rating the various wayfinding aspects}

Figure 10a, shows the results from the online survey and indicates the level of ease to difficulty end users' experience when navigating complex campus environments. When the average of the respondents scores are calculated, it would indicate that participants had in general more difficulty locating resources and classes with a mean score of 3.4 each, closely followed by difficulty identifying campus information with a mean score of 2.9. Activities such as navigating tunnels and accessing maps had a mean score of 2.8. Locating buildings on campus recorded a mean score of 2.6. Accessing signs and landmark were on average easier, 
with a mean of 2.3 and 1.8 respectively. Interpreting these results literarily, one could find on average that wayfinding at Carleton works best in terms of navigating tunnels and recognizing landmarks such as buildings. However, this is not exactly what the data conveys.

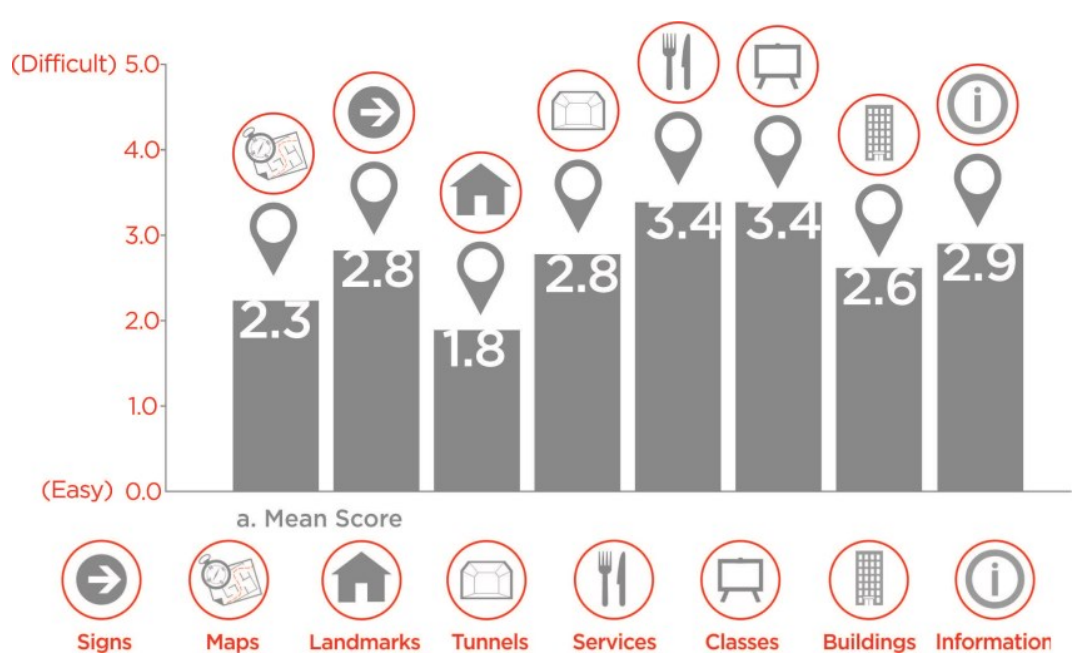

Figure 10a. Spatial design (activities) and icon keys: Ease of use (mean) (Oyelola, 2014)

The standard deviation of the results explained in the previous paragraph is illustrated in figure 10b. The standard deviation results indicate that there is a variation in the respondents' results. In other words, some respondents clearly find some of the wayfinding aspects more difficult than others. This could also indicate a variation in what people would define as difficult. As will be discussed further in Chapter 5, a survey of what people find easy or difficult is perhaps thus less relevant than obtaining specific feedback on problem areas. A survey could for example be manipulated to suggest that "most respondents find it is easy", whereas this might exclude certain populations and thus omit certain opportunities for design innovation. This will be examined further in Chapter 6 and study limitations in terms of outliers. 


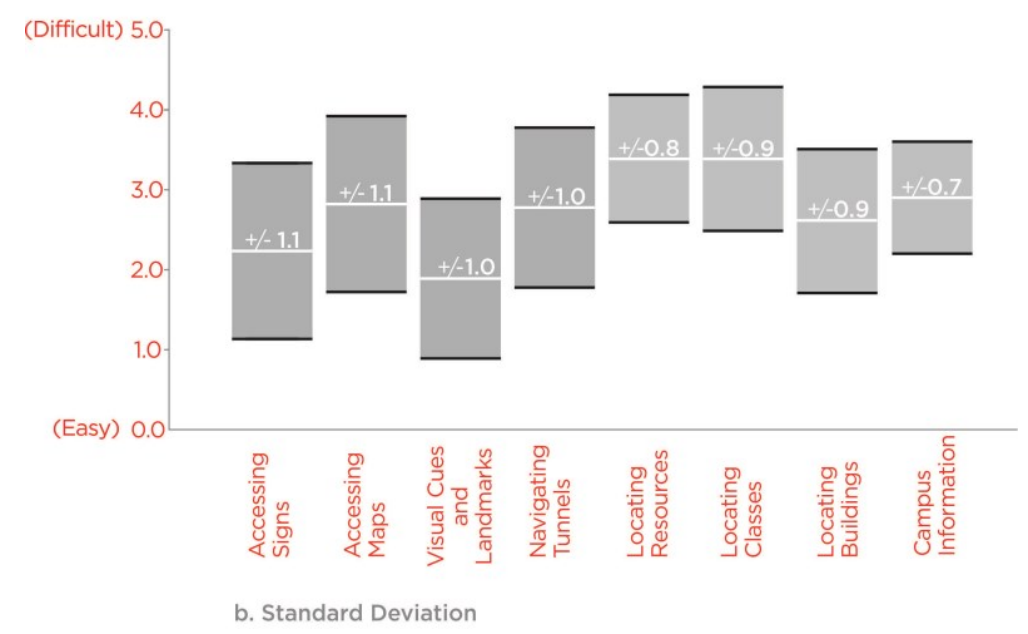

Figure 10b. Spatial design (activities): Ease of use (standard deviation) (Oyelola, 2014)

Figure 11a illustrates the level of significance end-users attach to spatial design characteristics, as they help enhance wayfinding when navigating. It indicates that participants attribute significance to use of graphic elements with a mean score of 2.4, closely followed by information clarity and campus accessibility with a mean score of 2.3. Information legibility and consistency both have a mean score of 2.0 each.

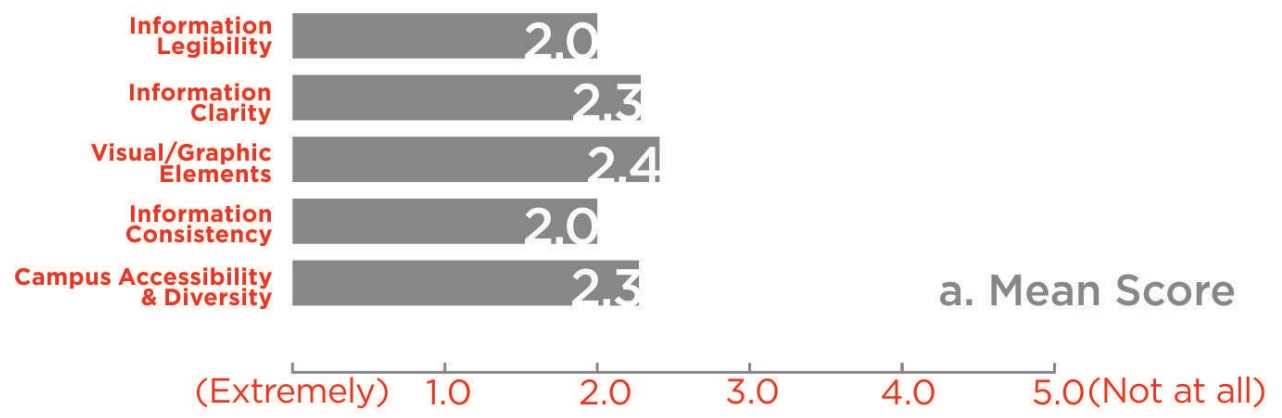

Figure 11a. Spatial design characteristics: Level of significance (mean) (Oyelola, 2014)

The standard deviation of the result above is illustrated in figure 11b. This also shows that there is a relatively high deviation across the spatial design characteristics. While some end 
users would consider these spatial design characteristics important, others would consider them less significant. Again, the idea of using outliers as part of the universal design approach would enable a design team to identify areas that could be designed more creatively, while perhaps first addressing needs of people with disabilities but making the whole campus benefit.

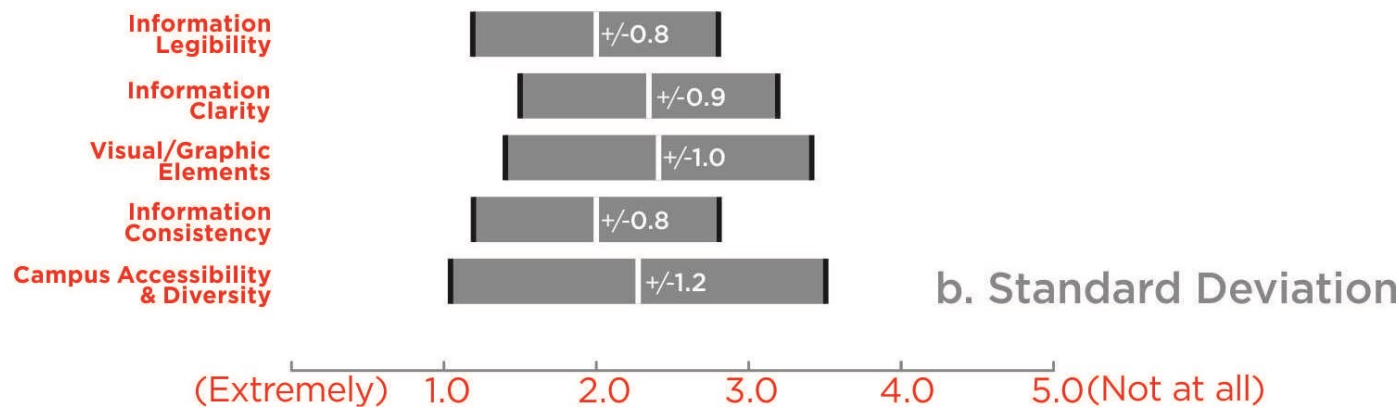

Figure 11b. Spatial design characteristics: Level of significance (standard deviation)

(Oyelola, 2014)

\section{$\underline{\text { Section } C}$}

This section provides corresponding insights into the results from the end-users' evaluation of the spatial design characteristics and corresponding activities in section B. Comments and remarks about spatial design, spatial communication, as well as suggestions for improvements in relation to wayfinding, were generated (see appendix F). These comments were organized into three distinct categories:

\section{Spatial Design}

Comments in the area of spatial design indicated issues in buildings on campus, especially Mackenzie and Loeb with respect to the rooms and the floor level system (see appendix G). Commenters also expressed dissatisfaction with the way the room numbers are 
arranged, which made it difficult for students to locate classes. In addition, respondents offered comments such as "The tunnels make the floor level system confusing" and "often one starts on the '2nd' floor when in reality this is ground level..." These respondents clearly indicate displeasure with the design of the floor level system and the inclusion of the tunnel, which made the floor level information confusing. This observation further explains why some people find the tunnels difficult to investigate.

\section{Spatial Communication}

Comments on spatial communication indicated that issues relating to maps and signs exist on the University campus (see appendix G for comments on maps and signs). These challenges encountered include unavailability of legible maps and signage that properly describes the space or location of the participants.

\section{Suggestions for Improvements}

In addition to the two areas of concern stated in the last two paragraphs, participants made more comments suggesting improvements. They indicated that spatial design features should be legible in terms of clarity and identities, making them stand out from each other. Another suggestion called for a review of the campus layout and building orientation. Finally, two participants mentioned the need for electronic systems that serve both as a wayfinding guide and information systems for ease of movement and program scheduling. 


\subsection{Evidence Source 3: Archival Document Analysis}

The themes that emerged from this document analysis were in line with the categories and themes that had already emerged in the evidence source 1 which include; context, benchmark, strategy, best practice, and funding.

\section{$\underline{\text { Context }}$}

The campus master plan addressed areas pertaining to planning and accessibility in the university environment, which includes navigation and exterior and interior site development. The master plan expresses commitments to spatial allocation with respect to pedestrian and vehicular movement that will ensure a barrier-free environment (Carleton University Master Plan, 2010). These commitments are aimed at ensuring that the tunnel system is integrated into every building to promote campus accessibility for all, including people with disabilities. The master plan also promotes the extensive use of external pathways for pedestrians and cyclists to ensure accessibility, with well-lit walkways at night and bicycle routes that lead to building entrances (Carleton University Master Plan, 2010). Please see Appendix I for details of the campus layout, including proposed development. Streets will also be redeveloped to ensure accessibility for rail/bus transit, commercial, private, service and emergency vehicles to buildings on campus. Furthermore, the plan proposes to contribute to the safety of end-users by ensuring clarity and legibility of lighting systems.

\section{Benchmark}

The University's website gives a brief description of its services, including quality improvement using a benchmarking model. This involves researching issues and challenges, identifying opportunities and deriving information from proven sources as a strategy for 
improvement and development. This process, which could also be referred to as a strategy for best practices, can be followed in the context of this study (Benchmarking, n.d.).

\section{$\underline{\text { Strategy }}$}

The strategic plan at Carleton University supports the basis of this study in terms of its core values, strengths and goals. In relation to the context of this study, its values include research excellence, interdisciplinary collaboration for solving complex problems, support for inclusivity in the physical environment, diversity and accessibility, as well as stewardship for excellence (Carleton University Strategic Integrated Plan, 2013). These values are the drivers needed to develop strategies for best practices in project execution, which involves participation, diversity and development.

\section{Funding}

The strategic integration plan also highlights funding as a criterion for achieving developmental goals (Carleton University Strategic Integrated Plan, 2009). Likewise, the Research Education Accessibility and Design (READ) initiative and the Paul Menton Centre for students with disabilities have a Dedicated Access Fund (DAF). DAF is partly supported by students' fees and partly by the University. The DAF is used to fund projects that involve people with disabilities.

\subsection{Results Summary}

This study focused on inclusive approaches and interdisciplinary processes in the design and development of accessibility and wayfinding systems at Carleton University. An understanding of contextual issues provided insight into the structural composition and strategic 
processes aimed towards inclusivity. Furthermore, insight into strategic aspects reveals the interdisciplinary process of identifying the different levels of stakeholders, their participatory roles and level of involvement.

Key stakeholders, especially those from the Space Management and Capital Planning department, have a major influence in making wayfinding design decisions, given that they craft policies, standards and implementation strategies concerning spatial planning, spatial information and facility and infrastructure management. What stood out most in the interviews, however, was the late involvement of designers who specialize in wayfinding design and planning projects.

Even experienced end-users express frustration at navigating the Carleton campus. The findings on infrastructure evaluation from the end-users showed that most have spent more than a year at Carleton. They have more challenges navigating inside buildings than outside (see Figure 9). More than half are visually oriented (i.e. the navigate using architectural cues) and most of the end-users were dissatisfied, citing problems with spatial design and communication features. This can be attributed to the complex nature of the university layout, the site topography, incongruent floor levels and the lack of environmental legibility. 


\section{CHAPTER 5 \\ DISCUSSION}

Elaborating on the finding from the previous chapter, this chapter discusses the main insights derived from the primary research.

RQ: How can the wayfinding design process be improved in University campuses?

SQ1: What best practices are involved in the wayfinding design process at Carleton? SQ2: How can these best practices for the wayfinding design process be improved at Carleton University?

\subsection{Best Practice at Carleton University}

Best practice involves doing more than the minimum standard required, which raises the bar for excellence and creates a benchmark for others to use.

\section{Standards and Accessibility on Campus:}

Most codes and standards are created to fit general situations, but consulting with a variety of end-users and stakeholders will identify issues of concern to particular user groups. These consultations therefore provide an opportunity to develop inclusive solutions. An example of a problem for some end-users is having emergency exit signs without tactile and contrast features that would make them legible to people with visual impairments. If the visually impaired user group is taken into consideration, it makes sense to include tactile and contrast features that can allow them safe use of the building. 


\section{Initiatives and Policies:}

An initiative such as the READ initiative at Carleton helps identify problematic areas to be changed. Identifying problems clearly can then contribute to the development and implementation of best practices towards an inclusive environment (Story, 1998; Tobias, 1997). In addition, there should be policies around budgets, gatekeepers and document review before construction to ensure adherence to standards and to end-user needs.

\section{Funding:}

Funding is a critical factor in inclusivity planning. As Anne Richards and John Aglie confirmed, funding can influence the quality of a design project. Given that quality must sometimes be compromised because of cost, the designer or consultant will be faced with the dilemma of delivering a quality installation at a loss or delivering a lower quality installation to meet budget constraints. Anne Richards recommends tackling projects in phases as a strategy to overcome budgeting challenges, since this increases the client's ability to match costs.

\subsection{Improving Best Practice at Carleton University}

In this study, it becomes relevant to highlight the significance of interdisciplinary collaboration (see chapter 2, Section 2.4.2.) and stakeholder participation (see chapter 2, Section 2.5.). These two processes made it clear that identifying stakeholders and their respective roles leaves room for effective outcomes of wayfinding projects, where functional usability is the focus of the outcome.

As described in the previous chapter, end-users expressed the need for functional usability in spatial design and communication features. This reflected on the comments endusers highlighted, especially the suggestions for improvement (see appendix G). These 
suggestions relate to environmental legibility and identity, as well as innovative approaches to graphic information systems.

\section{Early Involvement of Designers:}

In order to meet these expectations for functional usability, the designer must be involved in the initial stages, especially in terms of wayfinding design and accessibility. This is in contrast to current practice: design consultant stakeholders indicated that they are usually involved either midway or at the final stage of spatial design projects. When designer involvement is delayed until later stages, there are often problems with dysfunctional wayfinding systems or incongruent systems that can confuse, stress and frustrate the end-user.

Stewart Bailey expanded on the implications of delayed consultation with designers. He confirmed that in most spatial design projects, facility managers do not employ the service of a wayfinding design specialist at the development stage but only at the final stage, resulting in ad hoc arrangements. He noted that these ad hoc arrangements tend not to work in the long run; there are facility breakdowns during occupancy and complaints from end-users about getting lost in the facility. Bailey pointed out that this can give a negative impression of the organisation and it wastes staff time in directing people. This can be avoided if designers are involved at the developmental stage. He cited the example of a hospital project that stressed the importance of an understanding of end-users' perceptions from the start. Questionnaires were distributed to staff members and visitors were interviewed. This yielded sufficient information to guide design, enhancing the functional usability of wayfinding and accessibility systems.

Furthermore, the comment made by Mathew Cole, the Campus Residence Building Service representative and Janet Bewell, Senior Experience Architect/Psychologist, points to the fact that the campus community needs to respond to the complaint made by the end-users. 
This further creates a distinction between designing for aesthetics and designing with a user centered and empathetic mindset, as the role of designers are often assumed to be based on aesthetics alone, hence the late involvement at the final stage of the wayfinding design development.

\section{Locating end users and outliers:}

Designing with a user-centered and an empathetic mindset will put a focus on addressing the needs of end-users, which include using outliers. Surveys are tools that can reach a lot of the university campus population including staff and students as well as visitors. The study carried out in this thesis, albeit small, had two important observations. Firstly, it showed that multiple choice questions and semantic scales can be generally used to solicit feedback about peoples' perception on what works and what doesn't. Secondly, the standard deviation of these results indicated a high variation, as a result of the small sample size, which points to the fact that not everyone perceives navigation issues equally. This is why the results in section $\mathrm{C}$ are so significant; they highlight some issues that provide qualitative and empathetic insight into specific problems experienced by some respondents. As a result, these insights may differ from the average opinion on campus, hence outliers. Furthermore, ignoring specific feedback from respondents could mean leaving out opportunities that can benefit everyone in the end. At Carleton University and any other university, people with special needs including physical, visual, and psychological, represent a population that qualify as outliers. At the same time, outliers may simply be people who have made specific observations about specific problems or opportunities that could be used by designers to formulate new ideas. Following an empathetic approach helps designers understand the need of outliers, for instance design researchers can create scenarios similar to those visually impaired end-users experience. This approach helps 
the design consultant understand the flaw in the wayfinding design that will usually be overlooked. Having this mindset is crucial to the design process at the initial stages of design development, as this will inform design decisions that can ultimately promote effectiveness and usability (see Chapter2, Section 2.4.1.1.). It is important to point out that this is different from merely writing specifications and handing them off to designers later in the process. If designers are involved earlier in the design process then it is incumbent that they realize the complex contextual aspects of designing wayfinding for a university campus. In addition, designers can take a cue from Teresa Sapey and Dan Formosa by consulting with a wider end user group to identify their needs and collaborate with members of interdisciplinary teams to develop innovative and creative concepts that can benefit the entire Carleton campus population (see chapter 2, Page 25). 


\section{CHAPTER 6}

\section{CONCLUSION}

This chapter presents the conclusions reached from this investigation. The case study research presented here focused on the interdisciplinary processes and social participatory activities that improve inclusion and wayfinding design in a complex university campus. Further inquiry led to a discussion of inclusive activities, stakeholder participation, the designer's role and end-user involvement, all within the context of Carleton University. The study involved a critical review of relevant thematic areas such as accessibility, human performance, inclusivity in practice and evidenced-based research in practice. Three methods of evidence collection were used to engage three categories of stakeholders (design consultants, organisation staff and end-users) in order to generate insights into how to improve inclusivity and wayfinding design at the study site. This inquiry revealed that the first category of stakeholders, the organisation staff, were the key decision makers in the areas of wayfinding design and in terms of policies, standards and implementation related to spatial planning, spatial information and facility and infrastructure management. Design consultants, who form the second category of stakeholders, are consulted at later stages of spatial design projects. The third category of stakeholders are the end-users, primarily the students who are in direct contact with the facility.

On the basis of these investigations, central research questions were formulated:

RQ: How can the wayfinding design process be improved in University campuses? SQ1: What best practices are involved in the wayfinding design process at Carleton? SQ2: How can these best practices for the wayfinding design process be improved at Carleton University? 
These questions led the researcher first to define the context of the research, which shed more light on the structural composition and strategic processes involved in creating inclusive environments. Following this, findings about inclusive activities, interdisciplinary processes involved in the process, the role of design and the end-user were derived.

\subsection{Implications of Study}

The case study site was chosen because of its complex spatial structures, its interdisciplinary background and its strategic aim of being an accessible and inclusive institution. These features made it possible to investigate interdisciplinary processes and social participatory activities. The interdisciplinary process makes it possible to identify the stakeholders, and understand their role in the interdisciplinary process. This is important in the spatial design development of complex university environments because it helps each stakeholder assume and perform their role effectively.

\section{Best practice and the design process:}

Best practice encourages professionalism, excellence and dynamism (Sherman \& Sherman, 2012). A professional inclusive environment should have procedures in place that can serve as a benchmark for other institutions, both locally and globally. It should be a model for others to emulate. For an inclusive environment to be dynamic it has to have the capacity to adapt to new challenges, which involves reviewing and improving standards based on these challenges. Adapting to new challenges does not mean that standards should be compromised; it just implies that the standards should better accommodate a larger end-user group.

Appropriate funding is also crucial to the existence of a project that promotes inclusivity. Carleton accomplishes this through a Dedicated Access Fund (DAF), which was set up to 
provide financial resources to improve accessibility for people with disabilities. In addition, the budget of a project should not affect the quality of the outcome. That is to say, quality should not be compromised for budgetary reasons where functional usability for end-users is concerned, as inferior quality could cause harm to the end-user.

\section{Improving Best Practice:}

Involving designers earlier in the design process: Strategies for design development should be established before any project commences. This will help maintain best practice and professionalism when making decisions. Key stakeholders should consult with design experts who specialise in wayfinding design at the initial stage of the project to eliminate problems associated with having dysfunctional wayfinding systems at the post-occupancy stage. Design experts should aim for effectiveness and functional usability in all projects. This can be achieved by undertaking user research studies at the initial stage of design development, consulting with outliers and people with disabilities and use evidence-based research methods to understand user needs and perceptions.

Understanding the needs of end-users and outliers: By understanding the needs of endusers and outliers, the designer ensures that the design is functional, innovative and easy to use. While aesthetic concerns are valuable, functionality gives meaning to the design and makes it useable, therefore usefulness must come first. These outcomes can be achieved by focusing on a user-centered and empathetic approach. Furthermore, adequate research into understanding user needs and perceptions create evidence-based insights that can be applied to design projects at the early stage of design. These evidence-based methods can include the use of semi-structured interviews with open-ended questions, surveys and post-occupancy evaluation reviews as well as feedback from outliers. 


\section{Lessons from Teresa Sapey and Dan Formosa:}

Teresa Sapey: Contemporary and creative approach: Designers can take a cue from Teresa Sapey's work at the Hotel Puerta America car parking. This can influence contemporary and creative approaches to wayfinding development. These approaches could include branding as a wayfinding technique to promote the institution's identity, as well as to create a sense of place. This could be achieved by using a combination of color coding techniques, wall decals and lighting effects. This in the long run will not only ease stress and reduce wayfinding inefficiencies, but will enhance the social and dynamic nature of the university. What this highlights is that way finding is not only about soliciting data and feedback about problems. It is also about proposing and testing new forms of ideas and solutions that can influence and change the entire experience.

Dan Formosa: Inclusive design research strategies: Furthermore, applying inclusive design as a research strategy, could include using outliers and people with disabilities at the initial stage of design to ensure effective, easy to use and innovative design outcomes. Outliers includes all those people who clearly identify problems in navigating the campus and that can point to specific problem areas as possible areas for improvement. In the research survey it was clear that people perceived the ease of navigation differently. Those who found it harder could also identify specific issues they had with navigation.

\subsection{Contribution}

This study provided an in-depth investigation into the interdisciplinary and participatory processes involved in the design and development of wayfinding and accessibility systems in complex university environments. The main contributions to the field of design include the following: 
- Designers can contribute to the interdisciplinary collaboration processes involved in spatial design projects, which includes stakeholder identification, role identification and stage of involvement.

- Designers need to be aware of inclusive practices such as understanding the importance of special population like people with disabilities and other outliers that exhibit special needs.

- In addition, designers need to be aware of the creativity that goes beyond typical aesthetics standards and codes.

- Best practice at Carleton University can be modified so that designers can be involved at the initial stage of design projects, which could enable more creative and inclusive output.

- Furthermore, the designer must function as a design interlocutor between the end-user group and the design process and decision-making team. This includes understanding end-users' needs, concerns and perceptions, and translating them into valuable data for the design process. Evidence accumulated by design experts can be used as a standard for best practices.

\subsection{Limitation and Future Research}

This study had 8 participants for the semi-structured interview and 10 participants for the survey. Increasing the number of participants and sample size could generate more responses that are varied in order to strengthen the study in future research. This includes interviewing more interdisciplinary stakeholders and campus staff as well as extending the enduser survey to more students especially those with disabilities on campus. However, it should be noted that with regard to data interpretation, using a semantic scale is not enough to try to identify where the general consensus lies in terms of how hard or easy it is to navigate. If wayfinding is to improve and be more innovative in design, then the feedback from outliers 
may in fact be more important in terms of identifying specific design opportunities and problems. Including these will not only enhance the data collected but will produce more insights in future research. In addition, expanding the design research methods employed from this study to other universities to see if similar outcomes emerge could be useful. 


\section{POSTSCRIPT}

The process of researching wayfinding at Carleton University and analysing the findings has made me understand the relevance of interdisciplinary collaboration and social participation amongst stakeholders, who in this research context were the university staff, designers and students. It gave me a better understanding of the perceptions and needs of end-users as well as the perspectives of the designers involved in wayfinding projects in complex campus environment such as Carleton University. Four crucial aspects emerged in the design research of this thesis: the conceptual, strategic, interdisciplinary and social participatory aspects. These form a perfect starting point for the improvement of existing facilities and the development of new structures on the university campus. I will like to add that designers can develop and adopt contemporary and creative approaches to wayfinding development. These approaches could include branding as a wayfinding technique to promote the institution's identity, as well as to create a sense of place. This could be achieved by using a combination of color coding techniques, wall decals and lighting effects. In the long run this will not only ease stress and reduce wayfinding inefficiencies, but will enhance the social and dynamic nature of the university. 


\section{REFERENCES}

Accessibility for Ontarians with Disabilities Act, 2005: Design of Public Spaces Standards (Accessibility standards for the built environment). Retrieved from http://www.elaws.gov.on.ca/html/source/regs/english/2012/elaws_src_regs_r12413_e.htm

Alexander, C. (1964). Notes on the synthesis of form. Cambridge, MA: Harvard University Press.

Al-Tal, S. M. (2002). Integrated universal design: A solution for everyone. (Ph.D., Union Institute and University). ProQuest Dissertations and Theses. (305495403).

Arthur, P., \& Passini, R. (1992). Wayfinding: People, signs, and architecture. Toronto, ON: McGraw-Hill Book Co.

Beck, D. \& Wood, R.J. (1976). Cognitive transformation of information from urban geographic fields to mental maps. Environment and Behavior, 8, 199-238.

Bell, P.A., Greene, T.C., Fisher, J.D., \& Baum, A. (1996). Environmental psychology. Fort Worth: Harcourt Brace College Publishers.

Ben-Moshe, L., \& Powell, J. J. W. (2007). Sign of our times? revis(it)ing the international symbol of access. Disability \& Society, 22(5), 489-505. doi:10.1080/09687590701427602

Borun, M. (1977). Measuring the immeasurable: A pilot study of museum effectiveness. Washington, D.C.: Association of Science-Technology Centers.

Boudon, P. (1972). Lived-in architecture: Le Corbusier's Pessac revisited. Cambridge, MA: MIT Press. 
Brooks, R., \& Kleiner, B. H. (2003). How to comply with the Americans with Disabilities Act. Equal Opportunities International, 22(6/7), 9-16.

Bühler, C. (2001). Empowered participation of users with disabilities in universal design. Universal Access in the Information Society, 1(2), 85-90.

Chan, E. H. W., Lee, G. K. L., \& Chan, A. T. S. (2009). Universal design for people with disabilities. Property Management, 27(2), 138-146. doi:10.1108/02637470910946435

Chang, H. (2013). Wayfinding strategies and tourist anxiety in unfamiliar destinations. Tourism Geographies, 15(3), 529-550. doi:10.1080/14616688.2012.726270

Clarkson, J. (2003). Inclusive design: Design for the whole population. London and New York, NY: Springer.

Creswell, J. W. (1998). Qualitative inquiry and research design: Choosing among five traditions. Thousand Oaks, CA.: Sage Publications.

Da Silva, F. M. (2010). Accessibility and inclusion: The case study of the faculty of architecture of Lisbon. Advances in Cognitive Ergonomics, 230-240.

Danford, G. S., E. (1999). Measuring the influences of physical environments on the behaviors of people with impairments. Enabling Environments, 111-137.

De Couvreur, L., \& Goossens, R. (2011). Design for (every) one: Co-creation as a bridge between universal design and rehabilitation engineering. Codesign, 7(2), 107-121. doi:10.1080/15710882.2011.609890 
Devlin, A. S., \& Bernstein, J. (1995). Interactive wayfinding: Use of cues by men and women. Journal of Environmental Psychology, 15(1), 23-38.

Dischinger, M., \& Jackson Filho, J. (2012). Can tactile tiles create accessible urban spaces? Space and Culture, 15(3), 210-223. doi:10.1177/1206331212445958

Downs, R. (2001). Wayfinding behavior: Cognitive mapping and other spatial processes. Journal of Regional Science, 41(3), 553-556.

Evans, G. W., Fellows, J., Zorn, M., \& Doty, K. (1980). Cognitive mapping and architecture. Journal of Applied Psychology, 65(4), 474-478. doi:http://dx.doi.org.proxy.library.carleton.ca/10.1037/0021-9010.65.4.474

Evans, G. W., \& McCoy, J. M. (1998). When buildings don't work: The role of architecture in human health. Journal of Environmental Psychology, 18(1), 85-94. doi:http://dx.doi.org.proxy.library.carleton.ca/10.1006/jevp.1998.0089

Farr, A. C., Kleinschmidt, T., Yarlagadda, P., \& Mengersen, K. (2012). Wayfinding: A simple concept, a complex process. Transport Reviews, 32(6), 715-743. doi:10.1080/01441647.2012.712555

Ferren, A. (2005,September 5). Madrid: Hotel silken puerta america. The New York Times, Retrieved from http://go.galegroup.com/ps/i.do?id=GALE\%7CA136025812\&v=2.1\&u=ocul_carleton\&it= $\mathrm{r} \& \mathrm{p}=\mathrm{AONE} \& \mathrm{sw}=\mathrm{w} \& \mathrm{asid}=\mathrm{ca} 875 \mathrm{e} 042 \mathrm{f} 2 \mathrm{f} 77 \mathrm{df} 1 \mathrm{deba} 9958 \mathrm{~d} 7 \mathrm{c} 8 \mathrm{~b} 5 \mathrm{~b}$ 
Ford, M. A., \& Torok, D. (2008). Motivational signage increases physical activity on a college campus. Journal of American College Health, 57(2), 242-244. doi:10.3200/JACH.57.2.242-244

Frumkin, H. (2006). “Cities, suburbs, and urban sprawl.” In N. Freudenberg, S. Galea, and D. Vlahov (eds.), Cities and the Health of the Public (pp. 143-175). Nashville, TN: Vanderbilt University Press.

Garling, T. (1989). The role of cognitive maps in spatial decisions. Journal of Environmental Psychology, 9(4), 269-278.

Garling, T., Book, A., Lindberg, E., \& Arce, C. (1990). Is elevation encoded in cognitive maps? Journal of Environmental Psychology, 10(4), 341-351.

Gibson, B. E., Secker, B., Rolfe, D., Wagner, F., Parke, B., \& Mistry, B. (2012). Disability and dignity-enabling home environments Elsevier. doi:10.1016/j.socscimed.2011.10.006

Goldstein, E. B. (2010). Sensation and perception. Belmont, CA: Wadsworth, Cengage Learning.

Golledge, R. G. (1992). Place recognition and wayfinding: Making sense of space. Geoforum, 23(2), 199-214.

Gossett, A., Gossett, A., Mirza, M., Barnds, A. K., \& Feidt, D. (2009). Beyond access: A case study on the intersection between accessibility, sustainability, and universal design. Disability \& Rehabilitation: Assistive Technology, 4(6), 439-450. doi:10.3109/17483100903100301 
Gray, J. A., Zimmerman, J. L., \& Rimmer, J. H. (2012). Built environment instruments for walkability, bikeability, and recreation: Disability and universal design relevant? Disability and Health Journal, 5(2), 87-101. doi:10.1016/j.dhjo.2011.12.002

Gibson, D. (2009). The wayfinding handbook: Information design for public places. New York, NY: Princeton Architectural Press.

Greene, J. (2010). Design Is How It Works: How the Smartest Companies Turn Products into Icons. New York, NY: Penguin.

Guy, B. S., Curtis, W. W., \& Crotts, J. C. (1990). Environmental learning of first-time travelers. Annals of Tourism Research, 17(3), 419-431. doi:10.1016/0160-7383(90)90007-E

Haake, R. J., Smith, R. N., \& Pick Jr., H. L. (1984). Wayfinding in unfamiliar environments. Infant Behavior and Development, 7, Supplement 1(0), 153.

Hassanain, M.A. (2007), "Post-occupancy indoor environmental quality evaluation of student housing facilities," Architectural Engineering and Design Management, 3, 249-56.

Heft, H. (1979). The role of environmental features in route-learning: Two exploratory studies of way-finding. Environmental Psychology and Nonverbal Behavior, 3(3), 172-185. doi:10.1007/BF01142591

Hirtle, S. C., \& Hudson, J. (1991). Acquisition of spatial knowledge for routes. Journal of Environmental Psychology, 11(4), 335-345. 
Huang, C., \& Yu, S. (2013). A study of environmental perception patterns of the visually impaired and environmental design. Indoor and Built Environment, 22(5), 743-749. doi:10.1177/1420326X12456317

Hund, A. M., \& Padgitt, A. J. (2010). Direction giving and following in the service of wayfinding in a complex indoor environment. Journal of Environmental Psychology, 30(4), 553-564. doi:10.1016/j.jenvp.2010.01.002

Imrie, R. (2012). Universalism, universal design and equitable access to the built environment. Disability and Rehabilitation, 34(10), 873-882. doi:10.3109/09638288.2011.624250

Imrie, R., \& Hall, P. (2001). Inclusive design designing and developing accessible environments. New York, NY: Spon Press.

Ingram, T. (2010). Parking garage, calle farmacia 12. Frame, (75), 62. Retrieved from http://search.proquest.com/docview/1473772481?accountid=9894

Kantrowitz, M., \& Nordhaus, R. (1980). The impact of post-occupancy evaluation research. Environment and Behavior, 12(4), 508-519. doi:10.1177/0013916580124007

Kato, Y., \& Takeuchi, Y. (2003). Individual differences in wayfinding strategies. Journal of Environmental Psychology, 23(2), 171-188.

Kernohan, D., Gray, J., Daish, J. (1992). User participation in building design and management: A generic approach to building evaluation (first ed.). Oxford, OX, Boston: Butterworth Architecture. 
Kitchin, R. M. (1994). Cognitive maps: What are they and why study them? Journal of Environmental Psychology, 14(1), 1-19.

Kovacs Burns, K., \& Gordon, G. (2010). Analyzing the impact of disability legislation in Canada and the United States. Journal of Disability Policy Studies, 20(4), 205-218. doi:10.1177/1044207309344562

Lawrence, R. (1981). Participatory architectural design. Simulation \& Games, 12(4), 499-507. doi:10.1177/0037550081124010

Levermore, G. J. (1994). Occupants' assessments of indoor environments: Questionnaire and rating score method. Building Services Engineering Research and Technology, 15(2), 113118. doi: $10.1177 / 014362449401500206$

Levine, M. (1982). You-are-here maps: Psychological considerations. Environment and Behavior, 14(2), 221-237. doi:10.1177/0013916584142006

Lynch, K. (1960). The image of the city. Cambridge, MA: The MIT Press.

Malinowski, J. C., \& Gillespie, W. T. (2001). Individual differences in performance on a largescale, real-world wayfinding task. Journal of Environmental Psychology, 21(1), 73-82.

Martins, L. B., de Lima, F. J., \& Xavier do Monte Almeida, Maria de Fatima. (2010). In Kaber D. B.,G. (Ed.), The decision-making process for wayfinding in close environments by blind people

Marshall, J. D., M. Brauer, and L. D. Frank. (2009). "Healthy neighborhoods: Walkability and air pollution.” Environmental Health Perspectives 117 (11), 1,752-1,759. 
Martins, B., Hanington, B. (2012). Universal Mathod of Design: 100 Ways to Research Complex Problems, Develop Innovative Ideas, and Design Effective Solutions. Beverly, MA: Rockport

McCormick, M. S. (1996). How to get there from here: Wayfinding in complex environments. (Ph.D., Texas A\&M University). Retrieved from ProQuest Dissertations and Theses, . (304359952).

McGrath, P. T., \& Horton, M. (2011). A post-occupancy evaluation (POE) study of student accommodation in an MMC/modular building. Structural Survey, 29(3), 244-252. doi:10.1108/02630801111148211

Mollerup, P. (2005). Wayshowing: A guide to environmental signage principles \& practices. New York, NY: Lars Müller.

Nowacek, N. (2005). Hotel Puerta America: Parking - Teresa Sapey. Metropolis, 25, 108-109. Retrieved from http://search.proquest.com/docview/1473834877?accountid=9894

O'Neill, M. J. (1991). Effects of signage and floor plan configuration on wayfinding accuracy. Environment and Behavior, 23(5), 553.

O'Neill, M. J. (1992). Effects of familiarity and plan complexity on wayfinding in simulated buildings. Journal of Environmental Psychology, 12(4), 319-327.

Ormerod, M. G., \& Newton, R. A. (2005). Moving beyond accessibility: The principles of universal (inclusive) design as a dimension in $\mathrm{nD}$ modelling of the built environment. Architectural Engineering and Design Management, 1(2), 103-110. doi:10.1080/17452007.2005.9684587 
Ormerod, M. G., \& Newton, R. A. (2005). Briefing for accessibility in design. Facilities, 23(7/8), 285-294. doi:10.1108/02632770510600254

Passini, R. (1984). Wayfinding in architecture. New York, NY: Van Nostrand Reinhold Company.

Peponis, J., Zimring, C., \& Choi, Y. K. (1990). Finding the building in wayfinding. Environment and Behavior, 22(5), 555-590. doi:10.1177/0013916590225001

Preiser, W. F. E. (1995). Post-occupancy evaluation: how to make buildings work better.

October, 13(11), 19-28.

PROFILE: Teresa sapey. (2007). Design Week, 22(30), 13. Retrieved from http://search.proquest.com/docview/215586996?accountid=9894

Rainwater, L. (1966). "Fear and the house-as-haven in the lower class." Journal of the American Planning Association 32 (1), 23-31.

Rapoport, A. (1969). House form and culture. Englewood Cliffs, NJ: Prentice-Hall.

Rocca, A. (2010). Parking design. Interni, 70-75,128. Retrieved from http://search.proquest.com/docview/1473789219?accountid=9894

Rousek, J. B., \& Hallbeck, M. S. (2011). The use of simulated visual impairment to identify hospital design elements that contributes to wayfinding difficulties. International Journal of Industrial Ergonomics, 41(5), 447-458. doi:10.1016/j.ergon.2011.05.002 
Schneider, L. F., \& Taylor, H. A. (1999). How do you get there from here? mental representations of route descriptions. Applied Cognitive Psychology, 13(5), 415-441. doi:10.1002/(SICI)1099-0720(199910)13:5<415::AID-ACP602>3.0.CO;2-N

Schweitzer, L. and J. Zhou. (2010). "Neighborhood air quality, respiratory health, and vulnerable populations in compact and sprawled regions." Journal of the American Planning Association 76 (3), 363-371.

Sebring-Cale, N. (2008). Accessibility issues with long-term disabilities. Neurological Research, 30(5), 437-440. doi:10.1179/016164108X269303

Sherman, S., \& Sherman, J. (2012). Design professionals and the built environment: Encountering boundaries 20 years after the Americans with Disabilities Act. Disability \& Society, 27(1), 51-64. doi:10.1080/09687599.2012.631797

Sanoff, H. (2000). Community participation methods in design and planning. New York, NY: Wiley.

Steinfeld, E., \& Maisel, J. (2012). Universal design: Creating inclusive environments. Hoboken, NJ: John Wiley \& Sons, Inc.

Stevenson, A. (1990). Signage. Facilities, 8(1) doi:10.1108/EUM0000000002090

Story, M. F. (1998). Maximizing usability: The principles of universal design. Assistive Technology, 10(1), 4-12. doi:10.1080/10400435.1998.10131955

Talbot, J.F., Kaplan, R., Kuo, F.E., \& Kaplan, S. (1993). Factors that enhance effectiveness of visitor maps. Environment and Behavior, 25, 743-760. 
Tobias, J. (1997). Universal design applied to business practices. Technology and Disability, $7(1-2), 63-71$

VanderKlipp, M. (2006). Develop a successful wayfinding system. Buildings, 100(4), 28-28.

Vischer, J. C. (2009). Applying knowledge on building performance: From evidence to intelligence. Intelligent Buildings International, 1(4), 239-248. doi:10.3763/inbi.2009.SI02

Weisman, J. (1981). Evaluating architectural legibility. Environment and Behavior, 13(2), 189204. doi:10.1177/0013916581132004

Whitmer, S. (2009). Does place really matter to students with learning disabilities? A study of three university campuses. Open House International, 34(1), 75-81.

Williams, C., Williams C. (1974). Craftsmen of necessity. New York, NY: Random House.

Xia, J. Arrowsmith, C., Jackson, M., \& Cartwright, W. (2008). The wayfinding process relationships between decision-making and landmark utility. Tourism Management, 29(3), 445-457.

Xie, H., Filippidis, L., Galea, E. R., Blackshields, D., \& Lawrence, P. J. (2012). Experimental analysis of the effectiveness of emergency signage and its implementation in evacuation simulation. Fire and Materials, 36(5-6), 367-382. doi:10.1002/fam.1095

Zacharias, J. (2001). Pedestrian behavior pedestrian behavior and perception in urban walking environments. Journal of Planning Literature, 16(1), 3-18.

doi: $10.1177 / 08854120122093249$ 


\section{GLOSSARY}

Circulation system This allows access from one space to another within the built environment. Examples are hallways, stairs and elevators.

Designer For the purposes of this thesis, the word "designer" refers to an individual who has been trained in a studio-based program such as industrial design, architecture or graphic design, where sketching methodologies are taught as part of the training syllabus.

Expert An individual with 10 or more years of experience in their field (Ericsson \& Smith, 1991) who has, as a result, developed distinct professional skills that are reflected in the way they solve problems in their field.

Functional inefficiency Refers to the dysfunctional state of spatial layout and communication systems that result to wayfinding difficulties in buildings. For example, a directional sign that points to the wrong direction.

Inclusive Design This involves designing environments for multiple end-users which involves improved performance and wellbeing that promotes social participation. 
make up the built environment. Examples are walls, floors, buildings. 
APPENDIX A

Semi-Structured Interview

(Introductory Emails) 


\section{Introductory Email (Expert Interview)}

Email Subject: Navigation at Carleton

Dear $<$ add name $>$,

My name is Kehinde Oyelola, and I am conducting a research on signage and navigation at Carleton University. I am a student of Master of Design at Carleton University, Ottawa, Canada. My co-supervisors are Professor Lois Frankel and Professor Bjarki Hallgrimsson from the School of Industrial Design and Professor Federica Goffi from School of Architecture.

Is there a possibility that <add company name $>$ might contribute to my study by volunteering an interview participant? In my research, <add company name $>$ has stood out because of its perspective on signage and navigation in institutional environments. Your participation would be appreciated as a valuable contribution to this research.

I am hoping that members of < add company name $>$ will find interest in this research, and we could arrange to meet via Skype, phone, or in-person in Ottawa or wherever is convenient for you. Please feel free to forward this message to any team members that you feel might be interested, and to contact me by email or phone (613-xxx-Xxxx) at your convenience. I have included some additional details of the study below.

Thanking you for your time and anticipation of your kind response.

Best regards,

Kehinde Oyelola

kehindeoyelola@cmail.carleton.ca

1 (613) xxx-Xxxx 


\section{Research Study: Navigation at Carleton University: An Interdisciplinary and}

participatory approach to investigating barriers to accessibility and effective navigation at Carleton University

This research involves Identifying and understanding issues about signage, accessibility, and navigation in public facilities (e.g. higher institutions). The sessions will be audio recorded, with an approximate duration of $30-60$ minutes. Participation in this study is entirely voluntary; participants may withdraw at up to May 15, 2014 without prejudice, and may omit answering any specific questions of their choosing.

\section{Participant Eligibility:}

Participants who work independently or in a firm that provides design services including wayfinding and solving navigation issues for public facilities (e.g. higher institutions).

The role of the participants includes industrial design, environmental psychology, architecture, environmental graphic design, etc.

\section{Study Duration:}

The interview portion of the study will take place between approximately March 28, 2014 and April 3, 2014. Each interview will require approximately 30 - 60 minutes, and can be scheduled at the participants' convenience.

If you would like more information regarding this thesis research, please email Kehinde Oyelola at kehindeoyelola@cmail.carleton.ca or call 613-xxx-xxxx. 


\section{Introductory Email (Staff Interview)}

Email Subject: Navigation at Carleton

Dear $<$ add Staff name $>$,

My name is Kehinde Oyelola, and I am conducting a research on signage and navigation at Carleton University. I am a student of Master of Design in Carleton University, Ottawa, Canada. My co-supervisors are Professor Lois Frankel and Professor Bjarki Hallgrimsson from the School of Industrial Design and Professor Federica Goffi from School of Architecture.

$<$ add department name $>$ perspective on $<$ add department role $>$ in relation to signage and navigation would be very much appreciated as a valuable contribution to this research.

I am hoping that members of $<$ add department name $>$ will find interest in this research, and that we could arrange to meet via Skype, phone, or in-person on campus or wherever is convenient for you. Please feel free to contact me by email or phone (613-xxx-xxxx) at your convenience. I have included some additional details of the study below.

Thanking you for your time and anticipation of your kind response.

Best regards,

Kehinde Oyelola

kehindeoyelola@cmail.carleton.ca

1 (613) xxx-Xxxx

Please note that this research has been reviewed and cleared by the Research and Ethics Board Carleton University, Ottawa. (Clearance expires on: 31 March 2015).

Should you have questions or concerns related to your involvement in this research, please contact the REB Vice-Chair/Coordinator, Leslie J. MacDonald-Hicks at ethics@carleton.ca or at 613-520-2517.

\section{Study Duration:}

The interview portion of the study will take place between approximately March 28, 2014 and April 3, 2014. Each interview will require approximately 30 - 60 minutes, and can be scheduled at the participants' convenience.

If you would like more information regarding this thesis research, please email Kehinde Oyelola at kehindeoyelola@cmail.carleton.ca or call 613-xxx-xxxx. 
APPENDIX B

Semi-Structured Interview

(Consent Form) 


\section{CONSENT FORM (Interview)}

\section{RESEARCH PROJECT TITLE}

An Interdisciplinary and participatory approach to investigating barriers to accessibility and effective navigation at Carleton University.

ETHICS CLEARANCE AND DATA COLLECTION DEADLINES: 31 May 2015

$$
\text { I, }
$$
agree on this day to participate in this research conducted by Kehinde Oyelola, a Master of Design Candidate at Carleton University.

Participant's Signature Researcher's Signature

\section{PURPOSE}

This research aims to identify and understand issues related to accessibility and effective navigation on Carleton University Campus. It seeks to understand the perception of people, design and non-design stakeholders, and the role design plays in the process.

\section{TASK AND DURATION}

You are asked to take part in a short interview session to identify and understand issues relating to signage and navigation at Carleton University (or University campuses in general). It will require approximately 30-60 minutes to complete. The interview will be audio recorded and transcribed.

\section{RISK CONCERNS}

There are no known emotional, physical, psychological risks involved in this research that can cause harm to the participants. There will also not be discriminatory questions that will cause discomfort to the participants. 


\section{ANONYMITY AND CONFIDENTIALITY}

You may request to have any portion of your responses not be attributed to you by contacting Kehinde Oyelola via email at kehindeoyelola@cmail.carleton.ca. In this case, these portions of the interview will be kept anonymous by being stored and reported separately from your attributed responses and any identifying information.

\section{RIGHT TO WITHDRAW}

You may omit answering any specific interview question, if you choose. You may withdraw from participation at any time before May 15, 2014. If you this is your choice, please contact the researcher via email at kehindeoyelola@cmail.carleton.ca and if you do withdraw from the study, all data collected from you will be destroyed.

This research has been cleared by the Research and Ethics Board with project number: 101264. If you have any question or concerns regarding any part of this research, Please feel free to contact the Research Ethics Board Coordinator and Vice Chair, Leslie MacDonald-Hicks at 6135202517 or ethics@carleton.ca, Kehinde Oyelola at 613 xxx xxxx or kehindeoyelola@cmail.carleton.ca, Lois Frankel at lois_frankel@carleton.ca. 


\section{APPENDIX C}

Semi Structured Interview

(Expert and Staff Interview Questions) 


\section{Expert Interview Questions}

\section{Context:}

- What major projects involving navigation have you worked on? What improvements did you make?

- What was involved in achieving this improvement?

- What are the issues/challenges and successes your (add company name) face in relation to accessibility and wayfinding?

- What challenge stands out most? And why?

- What factors do you consider when solving navigation issues?

\section{Strategy:}

- What strategies/polices do you adopt when solving wayfinding/ navigation issues.

- What are your views on design for inclusion?

\section{Interdisciplinary}

- From your perspective, what is your role in solving complex accessibility and navigation issues?

- At what stage of a project are you consulted, initial or close to completion?

- From your perspective, what do you think the role of design is in solving complex accessibility and navigation issues (in an institutional campus setting)?

- Whom do you usually collaborate with when working on a signage or navigation project?

- In addition, what was the experience like?

\section{Social Participation}

- What are the major complaint you get from the university community about accessibility and wayfinding?

- How does your department handle emergencies? 


\section{Staff Interview Questions}

\section{Context:}

- What are the issues/challenges and successes your department face in relation to accessibility and wayfinding on campus?

- What challenge stands out most? And why?

- What factors do you consider when solving navigation issues on campus?

\section{Strategy:}

- What strategies/policies do you adopt when solving (add department's role) cases in this context?

- Are there any initiatives in place?

- What are your views on design for inclusion?

\section{Interdisciplinary}

- From your perspective, what is your role in solving complex accessibility and navigation issues?

- At what stage of a project is your department consulted?

- Whom do you usually collaborate with when working on a signage or navigation project?

- In addition, what was the experience like?

\section{Social Participation}

- What are the major complaint you get from the university community about accessibility and wayfinding?

- How does your department handle them? 
APPENDIX D

Survey - Online Questionnaire (Recruitment email) 


\section{Email Subject: Navigation at Carleton (Survey-Online)}

Dear Friends,

My name is Kehinde Oyelola, and I am conducting a research on signage and navigation at Carleton University. I am a student of Master of Design in Carleton University, Ottawa, Canada. My co-supervisors are Professor Lois Frankel and Professor Bjarki Hallgrimsson from the School of Industrial Design and Professor Federica Goffi from School of Architecture.

Your experience navigating the university campus would be of great benefit to my research and I would like to invite you to take part in an online survey on the topic of signage and navigation at Carleton University.

The survey will take about 10-15 minutes to complete. For further details, please see the letter below, and the consent form linked to the survey. Please feel free to forward this message to fellow students who you feel might be interested, and to contact me by email or phone (613-xxx-xxxx) with any questions. The survey may be accessed through the following link: http://fluidsurveys.com/surveys/kehindeoyelola/barriers-to-navigation-incarleton-university/

Thank you for your time; I look forward to your participation and responses.

Best regards,

Kehinde Oyelola

MDes Candidate

Carleton University

kehindeoyelola@cmail.carleton.ca

1 (613) xxx-Xxxx 
Research Study:

Navigation at Carleton University: An Interdisciplinary and participatory approach to investigating barriers to accessibility and effective navigation at Carleton University 


\section{APPENDIX E}

Survey - Online Questionnaire (Consent Form) 


\section{Carleton}

U N I V E R S T Y

Canada's Capital University

\section{CONSENT FORM (Survey)}

\section{RESEARCH PROJECT TITLE}

An Interdisciplinary and participatory approach to investigating barriers to accessibility and effective navigation at Carleton University.

ETHICS CLEARANCE AND DATA COLLECTION DEADLINES: 31 May 2015

\section{PURPOSE}

This research aims to identify and understand issues related to accessibility and effective navigation on Carleton University Campus. It seeks to understand the perception of people, design and non-design stakeholders, and the role design plays in the process.

\section{TASK AND DURATION}

You are asked to take part in a short survey to identify and understand issues relating to signage and navigation in Carleton University. It will require approximately 10-15 minutes to complete.

\section{RISK CONCERNS}

There are no known emotional, physical, psychological risks involved in this research that can cause to the participants. There will also not be discriminatory questions that will cause discomfort to the participants.

\section{ANONYMITY AND CONFIDENTIALITY}

You may request to have any portion of your responses not be attributed to you by contacting Kehinde Oyelola via email at kehindeoyelola@cmail.carleton.ca. In this case, these portions of the survey will be kept anonymous by being stored and reported separately from your attributed responses and any identifying information. 


\section{RIGHT TO WITHDRAW}

Your participation in this study is entirely voluntary. You may omit answering any specific survey question, if you choose. You have the right to withdraw from the study at any point during, and up to a week after, your participation. If this is your choice, please contact the researcher via email at kehindeoyelola@cmail.carleton.ca You may withdraw from participation at any time before May 15, 2014 and if you do withdraw from the study all, data collected from you will be destroyed.

This research has been cleared by the Research and Ethics Board with project number:

\section{4}

If you have any question or concerns regarding any part of this research, Please feel free to contact Kehinde Oyelola at 613 xxx xxxx or kehindeoyelola@cmail.carleton.ca, Lois Frankel at lois_frankel@carleton.ca or the Research Ethics Board at:

Leslie MacDonald-Hicks,

REB Coordinator and Vice-Chair

Carleton University Research Ethics Board

1325 Dunton Tower

1125 Colonel By Drive

Ottawa, Ontario K1S 5B6

(613) 520-2517

ethics@carleton.ca

I accept that I have read and understand the conditions stated in this consent form attached to the email. I also accept to participate in this survey. 
APPENDIX F

Survey - Online Questionnaire

(Questions) 


\section{barriers to navigation in Carleton University}

\section{Consent}

By clicking on the link provided in the email, I accept that $i$ have read and understood the conditions stated in the consent form attached to the email. I also accept to participate in this survey.

$$
\text { I accept }
$$

\section{SECTION A:}

Please identify the option that best suit your situation

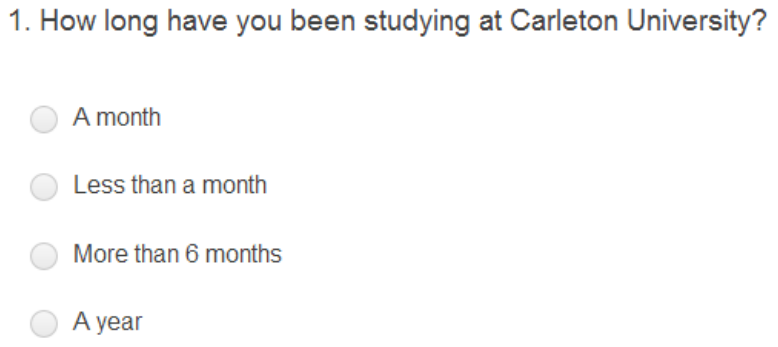

2. What personality type best represents you?

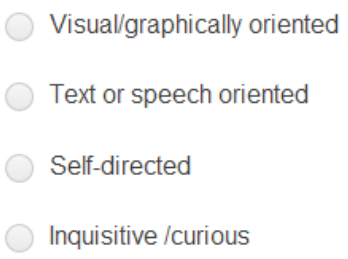

3 a. What is your perception about the navigation and accessibility system around the campus at Carleton University?
Satisfied
Indifferent
Dissatisfied

3 b. Please explain why

Type here 


\section{SECTION B:}

Please rate the following activities of navigation on campus, on a scale of 1 to 5 from easy to difficult

Finding and Interpreting signs
Finding and Interpreting maps
Recognising visual cues and
landmarks
Navigating through the tunnels
Locating resources within
buildings
Locating classes within
buildings
Locating a specific building
Getting information regarding
places on campus

Please rate the following characteristics in terms of significance for effective navigation

Clarity and legibility of
information
Frequency of information
Visual/graphical elements
Information consistency
$\begin{aligned} & \text { Accessible campus that } \\ & \text { encourages diversity }\end{aligned}$




\title{
SECTION C:
}

What has your experience getting around been like since you came to Carleton?

Type here

\author{
Type here
}

.

(1)

In a few words, how will you describe the existing navigation system on Carleton Campus?

Type here

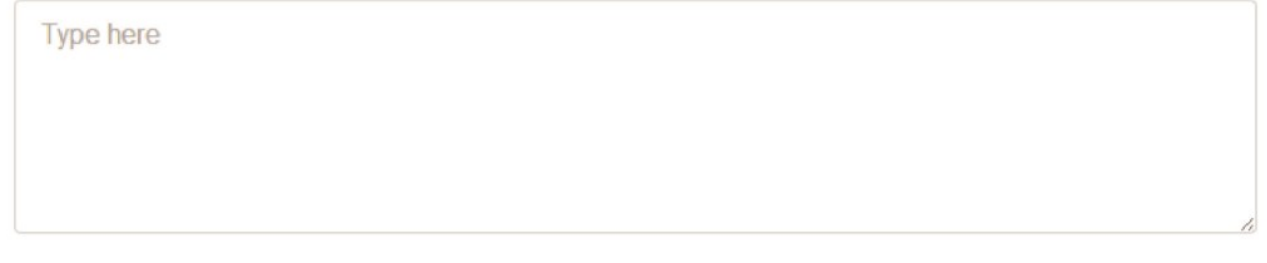

What challenges do you face in locating or getting to buildings or classes?

If you could have the opportunity to change anything to help you in finding your way around campus, what would that be?

Type here 
APPENDIX G

Survey - Online Questionnaire (End-User Comments and Suggestions) 


\begin{tabular}{|c|c|}
\hline Spatial Design & $\begin{array}{l}\text { Buildings: } \\
\text { "It was a steep learning curve..." } \\
\text { "I generally have no idea of the name or purpose of the building." } \\
\text { "The largest problem I have is trying to locate washrooms" } \\
\text { "..I still have no idea where they are" } \\
\text { "The buildings join and interconnect in ways that were not intended." } \\
\text { "because some buildings are complicated" } \\
\text { "In the tunnel there is no exterior visual references", } \\
\text { Rooms: } \\
\text { "finding a room for the first time was difficult } \\
\text { "Inconsistency with the numbering of rooms in buildings", } \\
\text { Floors: } \\
\text { "Different floor heights..." } \\
\text { "The tunnels make the floor level system confusing." } \\
\text { "Many floors have confusing layouts that make it tough to find your way." }\end{array}$ \\
\hline $\begin{array}{l}\text { Spatial } \\
\text { Communication }\end{array}$ & $\begin{array}{l}\text { Maps: } \\
\text { "... more maps distributed around campus and individual buildings maps" } \\
\text { "The maps posted throughout are helpful, but the building names are so small. } \\
\text { "It takes some time to orient oneself on the map and use it effectively." } \\
\text { "... but the maps themselves could be more efficient." } \\
\text { "Finding classes is complicated ... because there are no tiny maps"” } \\
\text { Signs: } \\
\text { "I would have better signs for that." } \\
\text { "The signage is available but only uses an arrow, but sometimes the arrow } \\
\text { doesn't point in the right direction, } \\
\text { "... sometimes there are so many arrows it takes long to read them all." } \\
\text { "It's confusing." }\end{array}$ \\
\hline More comments & $\begin{array}{l}\text { Suggestions for improvements } \\
\text { (legibility) Identity \& Distinctions: } \\
\text { "More graphic design, different colors for different buildings," } \\
\text { "At least for the current tunnels it would be cool to have colour coded "road" } \\
\text { lines to each building," } \\
\text { "Flatten and rebuild the campus." } \\
\text { "If I could I would start from scratch and reorient the building entirely." } \\
\text { E-maps and signage (Suggestions): } \\
\text { "develop a navigation app used for campus system that can locate all the rooms } \\
\text { and buildings." } \\
\text { "Live update of crowded halls or areas on the routes to class", }\end{array}$ \\
\hline
\end{tabular}


APPENDIX H

Archival Documents Analysis 


\section{Context:}

Carleton University Master Plan, 2010. Retrieved from http://carleton.ca/fmp/campusmaster-plan/

\section{Benchmarking:}

Benchmarking, n.d. Retrieved from http://www.carleton.ca/qualityinitiatives/oqiservices/benchmarking/

\section{Strategy:}

The Carleton University Strategic Integrated Plan 2013-2018. Retrieved from

http://carleton.ca/about/strategic-plan/

Defining Dreams: A Strategic Plan for Carleton University 2009. Retrieved from http://carleton.ca/about/strategic-plan/

\section{Best practice}

Carleton University Signage Standard Guide 2008. Retrieved from

http:/carleton.ca/fmp/our-services/space-administration/signage-and-way-finding/

Facilities Management And Planning: Space Management and Capital Planning, n.d.

Retrieved from http://carleton.ca/fmp/our-services/space-administration/space-

management/

\section{Funding:}

Paul Manton Centre: Dedicated Access Fund, n.d. Retrieved from 
http://www.carleton.ca/pmc/accessibility/funds

Paul Manton Centre: READ Initiative, n.d. Retrieved from

http://www.carleton.ca/pmc/read-initiative/

READ Initiative, n.d. (a) Retrieved from http://carleton.ca/read/

READ Institute First Year Report 2012 n.d. (b) Retrieved from http://carleton.ca/read/

READ Initiative: Mission Statement and Goals n.d. (c) Retrieved from

http://carleton.ca/read/about-read/mission-statement/ 


\section{APPENDIX I}

Carleton University

Spatial Layout \& Proposed Development 

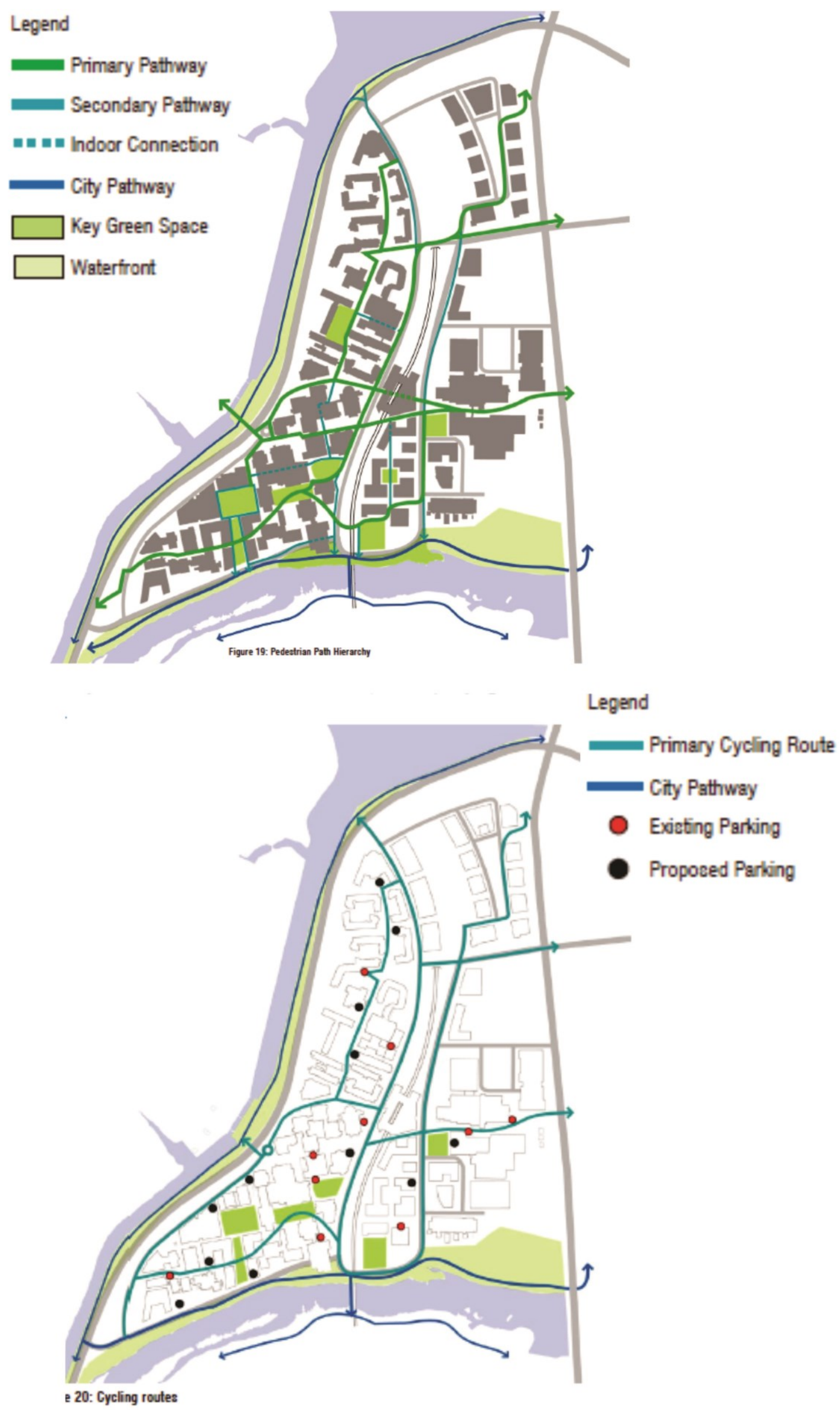

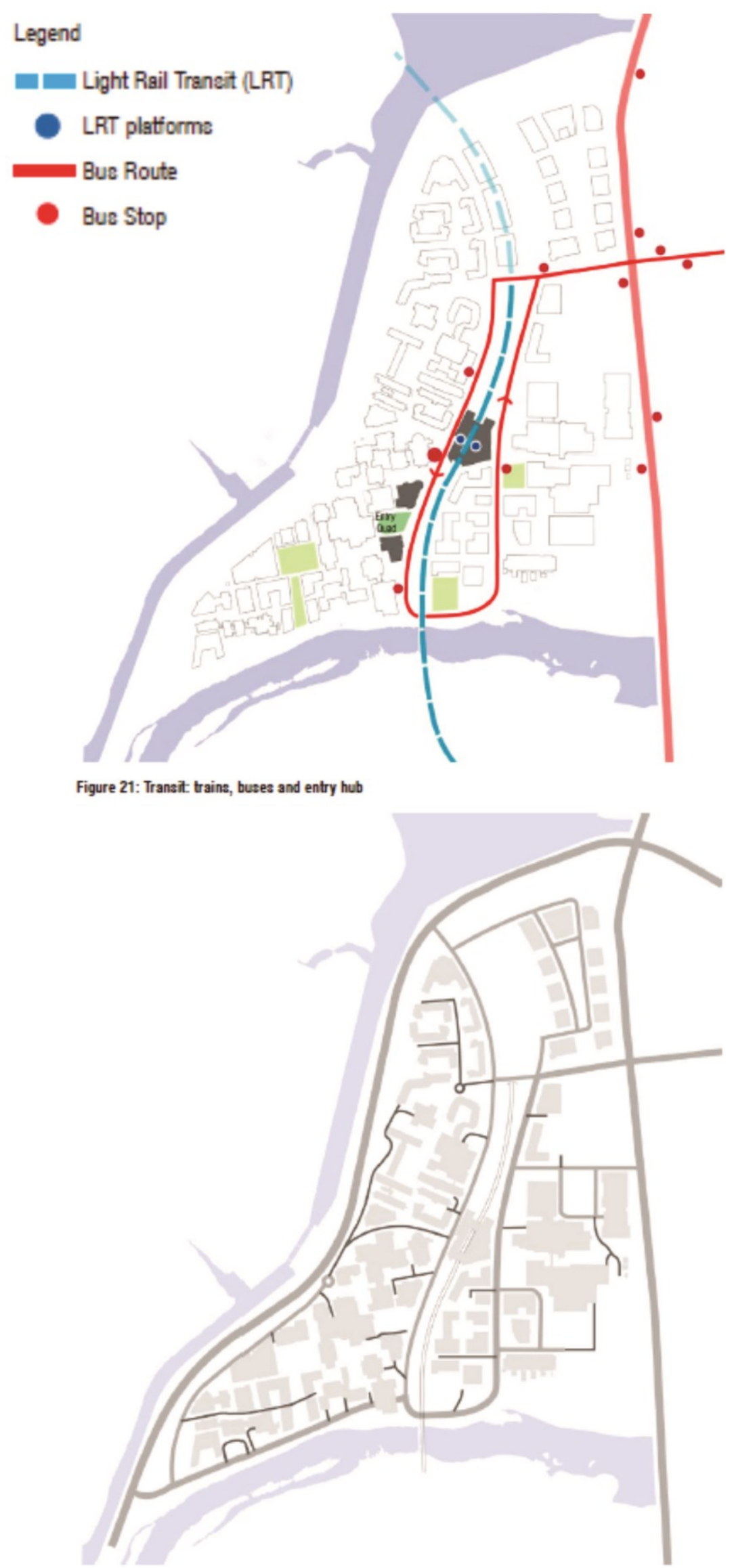

Figure 22: Service access 


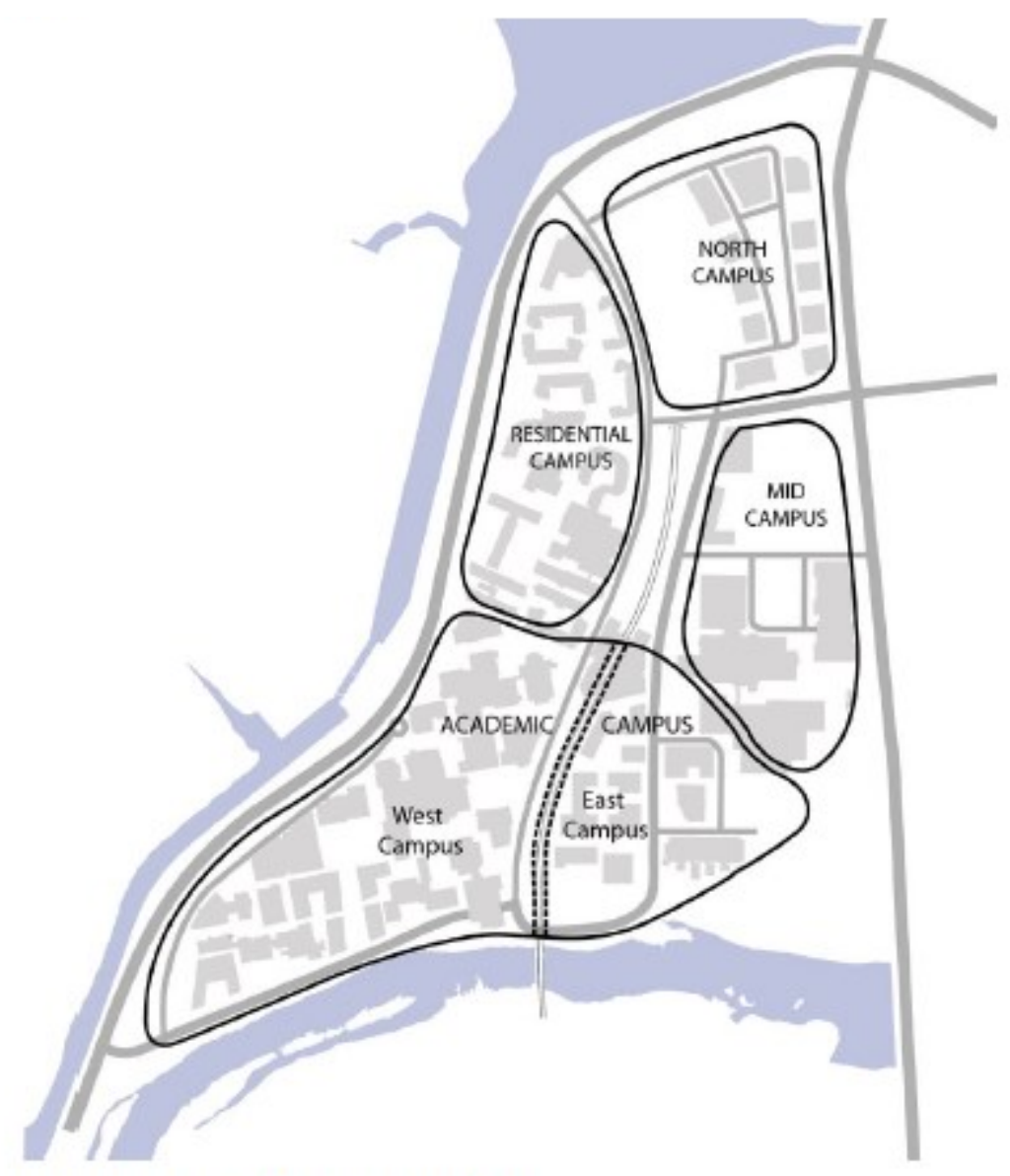


APPENDIX J

Interview Quotes

(Converging Categories and Themes) 


\begin{tabular}{|c|c|}
\hline \multirow[t]{11}{*}{ Design Strategies } & $\begin{array}{l}\text { Layout: } \\
\text { "You can find alternative routes involving elevator to avoid bad spots." } \\
\text { "we try to have all of the tunnel level be basement level or level one." }\end{array}$ \\
\hline & Environmental legibility: \\
\hline & $\begin{array}{l}\text { Signs and maps: } \\
\text { "The signs are built with the right contrast, so they can be seen. They are placed to } \\
\text { be seen by someone on the wheel Chair and someone standing." }\end{array}$ \\
\hline & "Another thing I look at is can you get to the signs?" \\
\hline & $\begin{array}{l}\text { "How close can you get to the sign? So all these other things such as color font, } \\
\text { location, its purpose and intuitive nature, size of letters and so on." }\end{array}$ \\
\hline & $\begin{array}{l}\text { we have different types of signage that can be easily identified. } \\
\text { "So, having a layby, pull over get a map and orient yourself on campus." } \\
\text { Another thing is that our exterior signs are reflective so at night, any vehicular lights } \\
\text { will illuminate them. }\end{array}$ \\
\hline & Sensory cues: \\
\hline & $\begin{array}{l}\text { When I say visual cues I look at the lighting, the size of signage, I look at the color, I } \\
\text { look at the background." }\end{array}$ \\
\hline & "I look at braille too. For signage, it is actually good." \\
\hline & $\begin{array}{l}\text { "The nice thing about braille is that you can put it up temporarily (it is flexible)." } \\
\text { "We put braille on the elevator buttons." }\end{array}$ \\
\hline & "safe paths which is our main pedestrian pathway through campus" \\
\hline
\end{tabular}




\section{Best Practice: "Yes, we have a policy to do more than the building codes"}

Standards, Policies "... the university adopted a set of standards for renovations and new buildings that will exceed the building codes."

and Initiatives

"The decision to ask the university to adopt a high standard of accessibility was not only in response to an individual issue."

"We need to do more to set a standard."

\begin{tabular}{|c|c|}
\hline $\begin{array}{l}\text { Human } \\
\text { Performance and } \\
\text { Diversity }\end{array}$ & "We provide a lot of support for students with visual impairments to learn their routes \\
\hline & $\begin{array}{l}\text { "But note that the route is always changing because there are different classes in different } \\
\text { buildings" }\end{array}$ \\
\hline
\end{tabular}

"So each term the students have to reorient themselves to the main areas to add these routes to their plans."

"That is one process. With the combination of people with any disability, it is very Individual.

"So for one person they might prefer to have a dog, use a cane, or they may just want to ask people for help.

"So it is very individual. You learn, work together to find the best way to navigate." 


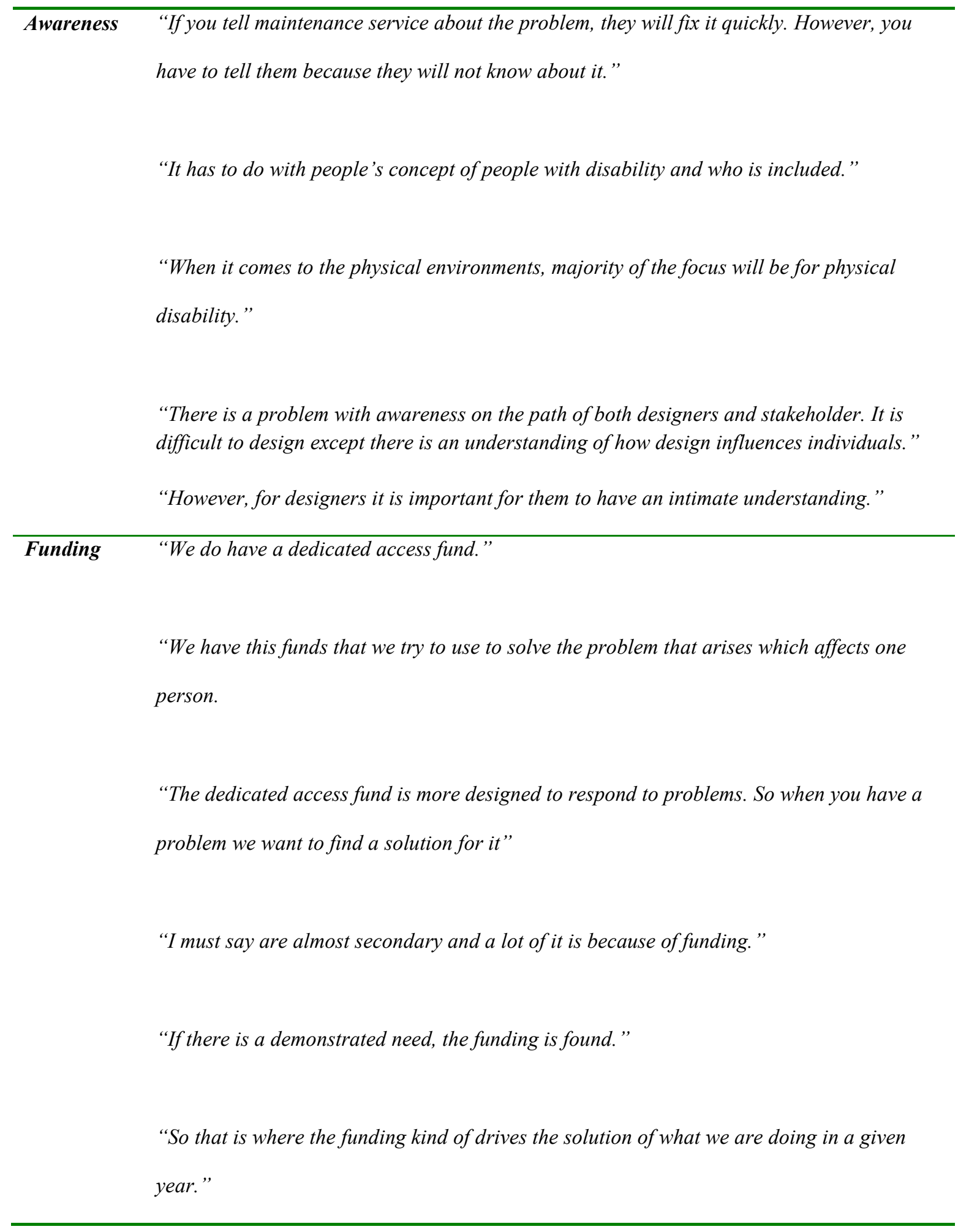




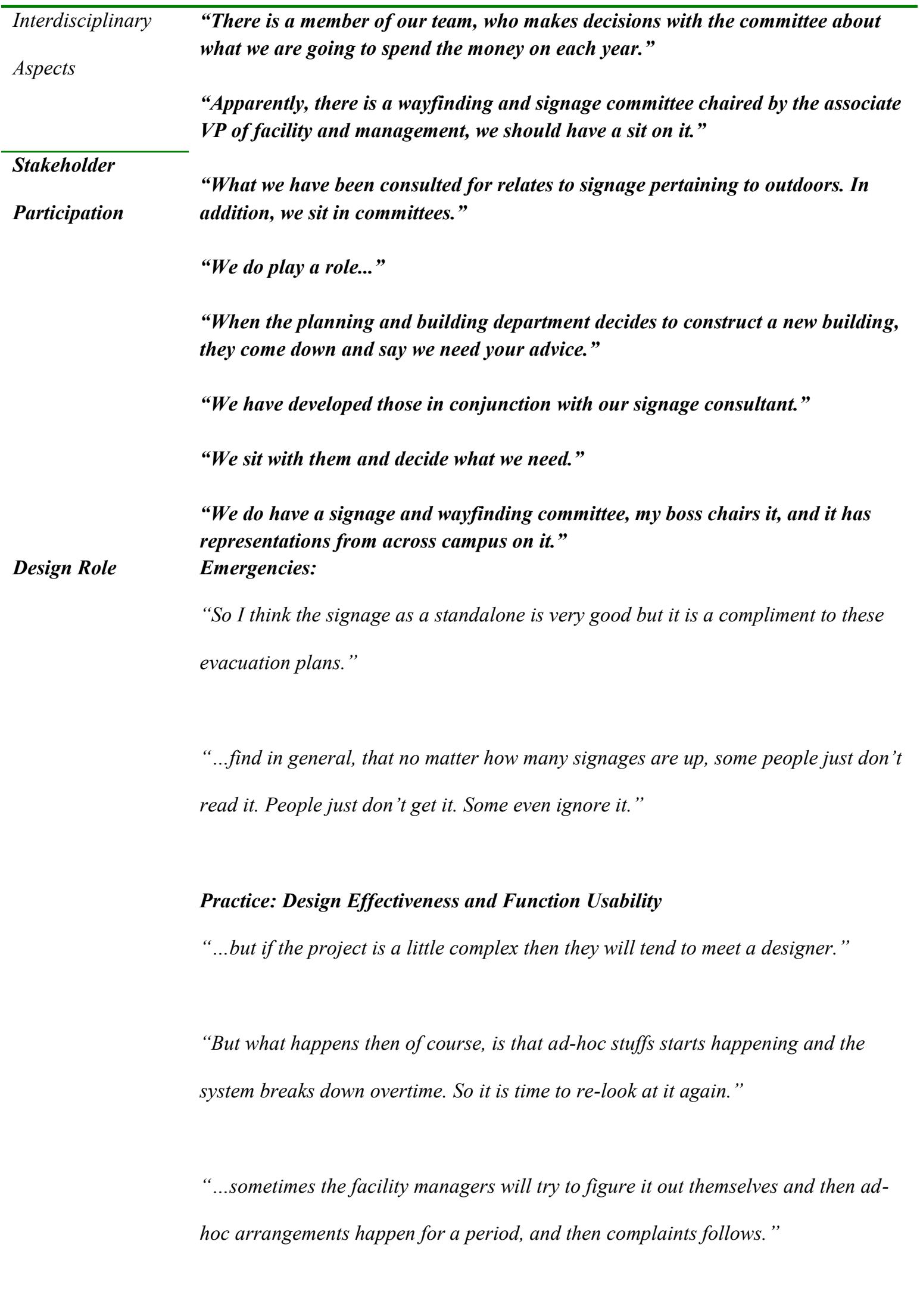


“...at some point either someone says it doesn't look very good or people are getting lost a lot, it is either of the two."

"So it is a huge challenge trying to solve a problem, that is like sticking a Band-Aid on a basic problem of a space not making sense."

I find that often wayfinding is a little bit of an afterthought

they are usually involve in a project too late to really influence the basic problems of the building.

"When dealing with the situation the architect is usually in my own opinion scrambling to deliver a project and is not too interested in hearing about anything he needs to change." 


\begin{tabular}{|c|c|}
\hline \multirow[t]{2}{*}{ Social Participation } & "But we had a lot of push back from the community saying." \\
\hline & "the users were complaining that..." \\
\hline \multirow[t]{3}{*}{ End-user Involvement } & $\begin{array}{l}\text { "...and consultation with administrators in the main offices, we reviewed the } \\
\text { content with them because they know the area best." }\end{array}$ \\
\hline & $\begin{array}{l}\text { "before we have our signs manufactured, we always get our end-users to sign off } \\
\text { on the content. So we don't want to presume what they want to call their different } \\
\text { rooms." }\end{array}$ \\
\hline & “...then john works with the end-users.” \\
\hline \multirow{4}{*}{$\begin{array}{l}\text { Infrastructure/Facility } \\
\text { Evaluation }\end{array}$} & $\begin{array}{l}\text { "...we listen to the end-users in the buildings so we have gone back and added } \\
\text { something that needed to." }\end{array}$ \\
\hline & $\begin{array}{l}\text { "...they come back with some really good comments saying we get this question all } \\
\text { the time." }\end{array}$ \\
\hline & "So we incorporate their feedback." \\
\hline & "So, we are constantly tweaking based on the needs that are expressed." \\
\hline
\end{tabular}

\begin{tabular}{|c|c|}
\hline Contextual Aspects & $\begin{array}{l}\text { "Carleton is a big campus and takes some time to learn, for anyone with disability } \\
\text { or not." }\end{array}$ \\
\hline Stakeholder & "With the building, we have different signage elements as well." \\
\hline \multirow[t]{8}{*}{ Participation } & "You don't know where you are when you are under ground." \\
\hline & $\begin{array}{l}\text { "May be we could talk a little bit about the tunnels because we don't have a map } \\
\text { for that." }\end{array}$ \\
\hline & "At Carleton, with what I have seen, we don't really have buildings with less than \\
\hline & two elevators because having one could be trouble." \\
\hline & “...it is hard to orient yourself and know what block you are in.” \\
\hline & “...they couldn't get to a place from here.” \\
\hline & “...people couldn't get their way into” \\
\hline & "The campus is broken down into five zones" \\
\hline
\end{tabular}




\section{Conditions}

"So I think the signage as a standalone is very good but it is a compliment to these evacuation plans."

“...find in general, that no matter how many signages are up, some people just don't read it. People just don't get it. Some even ignore it."

“...the elevator breaks down, they get stuck they can't get down, so we go get then by using evacuation chairs."

“...we have a better procedure in place called protect in place.

"So what was debated several years ago, was that when the alarm goes off, everyone is ordered out of the building in an orderly manner."

"You have to come up with a policy that assumes that if the fire alarm goes up there is danger."

"I think the fire response gets here about eight minutes."

"If the fire is containable, they contain it, but if it is a big thing, they start evacuating people starting with those closest to the hazard.

“... they are professionally evacuated by the fire department. So you can do this for four or twenty floors." 